\title{
Effect of Lactic Acid Bacteria on the Pharmacokinetics and Metabolism of Ginsenosides in Mice
}

\author{
Ji-Hyeon Jeon ${ }^{1}$, Jaehyeok Lee ${ }^{1}$, Jin-Hyang Park ${ }^{1}$, Chul-Haeng Lee ${ }^{2}$, Min-Koo Choi ${ }^{2, *}$ and Im-Sook Song ${ }^{1, *(D)}$ \\ 1 BK21 FOUR Community-Based Intelligent Novel Drug Discovery Education Unit, Vessel-Organ Interaction \\ Research Center (VOICE), Research Institute of Pharmaceutical Sciences, College of Pharmacy, \\ Kyungpook National University, Daegu 41566, Korea; kei7016@naver.com (J.-H.J.); \\ here0723@gmail.com (J.L.); wlsgid1957@naver.com (J.-H.P.) \\ 2 College of Pharmacy, Dankook University, Cheon-an 31116, Korea; hang1130@naver.com \\ * Correspondence: minkoochoi@dankook.ac.kr (M.-K.C.); isssong@knu.ac.kr (I.-S.S.); \\ Tel.: +82-41-550-1438 (M.-K.C.); +82-53-950-8575 (I.-S.S.); Fax: +82-53-950-8557 (I.-S.S.)
}

Citation: Jeon, J.-H.; Lee, J.; Park, J.-H.; Lee, C.-H.; Choi, M.-K.; Song, I.-S. Effect of Lactic Acid Bacteria on the Pharmacokinetics and Metabolism of Ginsenosides in Mice. Pharmaceutics 2021, 13, 1496. https:/ / doi.org/10.3390/pharmaceutics13091496

Academic Editor: Beom Soo Shin

Received: 16 August 2021

Accepted: 15 September 2021

Published: 17 September 2021

Publisher's Note: MDPI stays neutral with regard to jurisdictional claims in published maps and institutional affiliations.

Copyright: (C) 2021 by the authors. Licensee MDPI, Basel, Switzerland. This article is an open access article distributed under the terms and conditions of the Creative Commons Attribution (CC BY) license (https:/ / creativecommons.org/licenses/by/ $4.0 /)$.

\begin{abstract}
This study aims to investigate the effect of lactic acid bacteria (LAB) on in vitro and in vivo metabolism and the pharmacokinetics of ginsenosides in mice. When the in vitro fermentation test of RGE with LAB was carried out, protopanaxadiol (PPD) and protopanaxadiol (PPD), which are final metabolites of ginsenosides but not contained in RGE, were greatly increased. Compound $\mathrm{K}$ (CK), ginsenoside Rh1 (GRh1), and GRg3 also increased by about 30\%. Other ginsenosides with a sugar number of more than 2 showed a gradual decrease by fermentation with LAB for 7 days, suggesting the involvement of LAB in the deglycosylation of ginsenosides. Incubation of single ginsenoside with LAB produced GRg3, CK, and PPD with the highest formation rate and GRd, GRh2, and GF with the lower rate among PPD-type ginsenosides. Among PPT-type ginsenosides, GRh1 and PPT had the highest formation rate. The amoxicillin pretreatment $(20 \mathrm{mg} / \mathrm{kg} /$ day, twice a day for 3 days) resulted in a significant decrease in the fecal recovery of CK, PPD, and PPT through the blockade of deglycosylation of ginsenosides after single oral administrations of RGE $(2 \mathrm{~g} / \mathrm{kg})$ in mice. The plasma concentrations of CK, PPD, and PPT were not detectable without change in GRb1, GRb2, and GRc in this group. LAB supplementation ( 1 billion CFU $/ 2 \mathrm{~g} / \mathrm{kg} /$ day for 1 week) after the amoxicillin treatment in mice restored the ginsenoside metabolism and the plasma concentrations of ginsenosides to the control level. In conclusion, the alterations in the gut microbiota environment could change the ginsenoside metabolism and plasma concentrations of ginsenosides. Therefore, the supplementation of LAB with oral administrations of RGE would help increase plasma concentrations of deglycosylated ginsenosides such as CK, PPD, and PPT.
\end{abstract}

Keywords: red ginseng extract (RGE); lactic acid bacteria (LAB); ginsenoside metabolism; pharmacokinetics

\section{Introduction}

Red ginseng extract (RGE), one of the most popular herbal medicines, has been investigated for its efficacy. RGE not only reinforces immune function, but also has anticancer, anti-diabetes, anti-inflammation, antioxidation, and liver protective effects [1]. Ginseng glycoside, called ginsenoside, is a major active pharmacological component, which causes the efficacy of RGE [2-4]. The serum concentrations of GRg1 and GRb1 showed a good correlation with NO releasing effect, a marker for anti-inflammatory effect $[5,6]$. In addition, the safety, pharmacokinetics, and preliminary efficacy of CK as an anti-rheumatoid arthritis drug are under clinical investigation in China (Study No. NCT03755258) [7]. The plasma exposure of CK showed a linear increase over the oral dose range of 100-400 $\mathrm{mg}$ of CK tablet. CK was safe and well-tolerated for CK dose regimen (100-400 $\mathrm{mg}$ of $\mathrm{CK}$, once daily for 9 days) [8,9]. The plasma concentration of $\mathrm{CK}\left(\mathrm{C}_{\max } 254.5 \mathrm{ng} / \mathrm{mL}\right)$ in subjects who received $3 \mathrm{~g}$ fermented RGE (contains $10.9 \mathrm{mg}$ 
$\mathrm{CK})$ was substantially higher than that $\left(\mathrm{C}_{\max } 8.4-24.8 \mathrm{ng} / \mathrm{mL}\right)$ in subjects who received RGE (does not contain CK), suggesting the critical role of fermentation process using lactic acid bacteria (LAB) $[10,11]$. In a 4-week, randomized, double-blind clinical study of patients with allergic rhinitis, intake of fermented RGE $(750 \mathrm{mg} /$ day; contained $45.8 \mathrm{mg}$ CK) alleviated nasal congestion [12]. GRg3 and CK are effective against various human cancer cells as well as in tumor-bearing animal models in a dose-dependent manner [13]. GRg3 suppresses tumor growth and inhibits tumor angiogenesis by inhibiting vascular endothelial growth factor-dependent pathway [14]. GRg3 and CK induce apoptosis and cell cycle arrest at the G0/G1 phase and decreases drug resistance by inactivating nuclear factor kappa light chain enhancer of activated B cells (NF-kB) or a caspase-dependent pathway $[15,16]$. Administration of GRg3 tablet ( $20 \mathrm{mg}$ twice daily for 30 days) combined with gemcitabine and cisplatin in patients with advanced esophageal cancer increased the one-year survival rate and reduced drug-associated adverse events [15,17]. Meta-analysis of 20 clinical studies involving GRg3 (20 mg twice daily 6-24 weeks) combined with non-small cell lung cancer therapeutics indicated that Rg3 enhances short-term efficacy, prolongs overall survival rate, and reduces treatment-related toxicity [14,18-20]. Plasma exposure of GRg3 was increased 7.3-fold over the 6-fold dose range (10-60 mg, intramuscular injection) without a significant change in clearance and volume of distribution in Chinese healthy volunteers [21].

RGE showed anti-diabetic effect through the suppression of hepatic gluconeogenesis via the activation of adenosine monophosphate-activated protein kinase (AMPK) and peroxisome proliferator-activated receptors-gamma (PPAR $\gamma)$ and through the increased glucose uptake in adipocytes or skeletal muscle cells [22,23]. RGE fermented with Lactobacillus plantarum, which is involves in the deglycosylation of PPD-type ginsenosides [24], showed better antidiabetic effects compared with RGE treatment in the streptozotocin-induced diabetic mice [25]. Supplementation of hydrolyzed ginseng extract that are fermented to have higher content of GRg1, GRg3, and CK ( $960 \mathrm{mg} /$ day for 8 weeks) significantly decreased the levels of fasting plasma glucose and postprandial glucose in 12 impaired fasting glucose participants [26]. These reports suggested that the supplementation of RGE with higher content of pharmacologically active ginsenosides may have better anti-diabetic activity. Similarly, comparative studies on the efficacy of fermented RGE versus RGE were reported. Lee et al. [27] reported the increased anti-wrinkle efficacy, whitening efficacy, and reduced toxicological potency of fermented RGE that contains increased ginsenoside metabolites, such as GRg3, CK, GRh1, and GF2, compared to RGE. Nan et al. [28] reported that fermented ginseng with Lactobacillus fermentum ameliorated hyperlipidemia and liver injury induced by a high fat diet through the increased content of GRg3, GRh1, GRh2, and GF2. Bifidus fermentation increased the content of GRg3 and GRh2 and it increased hypolipidemic and hypoglycemic effects of RGE in hyperlipidemic mice [29]. These reports suggested that the fermentation of RGE with LAB may change the content of ginsenoside and the efficacy of RGE.

Many studies have focused on the role of LAB in the metabolism of ginsenosides. Ginsenoside has a sugar moiety structure bound to an oleanane and dammarane structure. Depending on the location of the carbon bond of the sugar chain, the type of dammaraneginsenoside is determined; it is either protopanaxadiol (PPD)-type or PPT-type [20,30,31]. Further subdivisions occur depending on the length of the sugar chain (Figure 1). Belonging to the PPD-type ginsenosides are GRb1, GRb2, GRc, GRd, GRh2, GF2, GRh2, CK, and PPD, whereas GRe, GRg1, GRf, GF1, GRh1, and PPT all belong to PPT-type ginsenosides [20]. Upon human administration, large molecular weight ginsenosides (they have long sugar chains, such as GRb1, GRb2, GRc, GRd, GRe, GRf, and GRg1) undergo deglycosylation by the intestinal microbiota to small molecular weight ginsenosides (have short sugar chains, such as GRh2, CK, PPD, GRh1, GF1, and PPT) [32-34]. Therefore, there has been a metabolic relationship in the subdivision of ginsenosides according to the deglycosylation status [32]. 


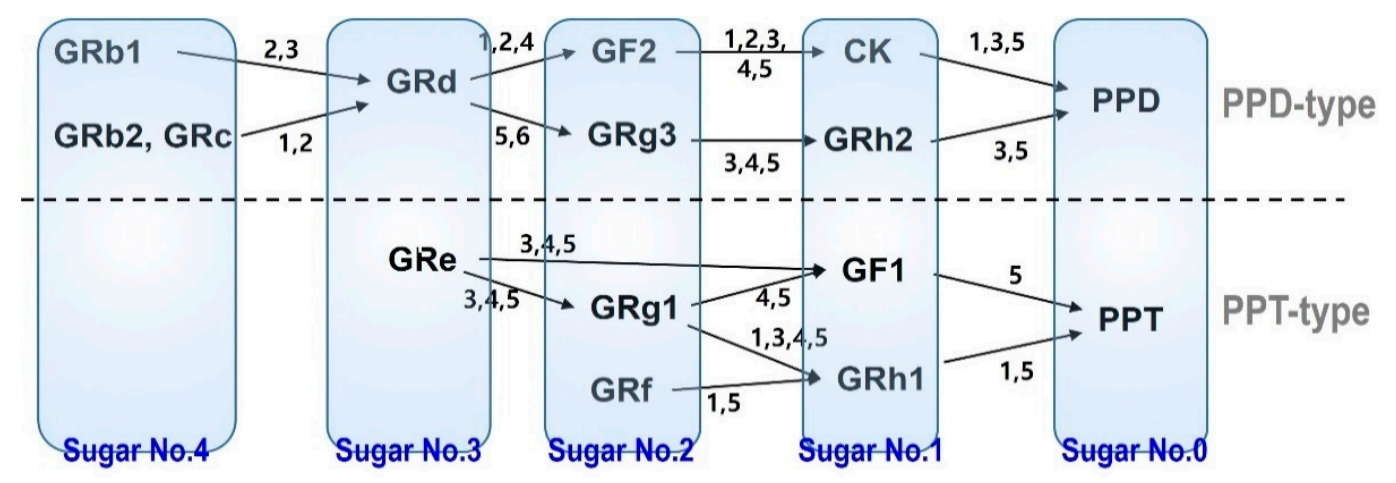

Figure 1. PPD- and PPT-type ginsenosides were grouped by the sugar number and the metabolic pathway of ginsenosides related to gut microbiota. 1: Bifidobacterium sp.; 2: Lactobacillus sp.; 3: Eubacterium sp.; 4: Fusobacterium sp.; 5: Bacteroides sp.; 6: Microbacterium sp.

The metabolism of ginsenosides is mediated by gut the microbiota, in which the involvement of LAB was reported (Figure 1) [32,35-38]; Lactobacillus sp. [32], Bifidobacterium sp. [39-44], Eubacterium sp., Fusobacterium sp., Bacteroides sp., and Microbacterium sp. [40,42-45]. More specifically, L. brevis is involved in GRd $\rightarrow$ GF2 $\rightarrow$ CK metabolism [39,41]. L. sakei [24], L. plantarum [24], and Bifidobacterium longum [46,47] are involved in GRb1, GRb2, GRc $\rightarrow$ GRd metabolism. B. longum was also involved in GRc $\rightarrow$ GRd metabolism. Mircobacterium sp. are involved in GRb1, GRb2 $\rightarrow$ GRd $\rightarrow$ GRg3 metabolism [37,38]. Bifidobacterium sp., Eubacterium sp., and Bacteroides sp. are generally involved in the PPD-type and PPT-type metabolism (Figure 1) [40,42-45].

LAB plays some roles in a part of metabolism or immune system [48]. With an increasing understanding of the beneficial role of $L A B, L A B$ is administered as health supplements and, therefore, the demand for LAB has grown rapidly. This has led to frequent co-administration of LAB and ginseng products. Additionally, based on the beneficial role, Combi-formulation of LAB and ginseng has been introduced in the Korean health supplement market. Moreover, information regarding the interaction between RGE and $\mathrm{LAB}$ is limited, although the involvement of LAB in the ginsenoside metabolism has been proven $[32,35,36]$. As most studies focused on the role of $L A B$ in in vitro ginsenoside metabolism, we investigated the effects of LAB on in vivo ginsenoside metabolism and the resultant pharmacokinetics of ginsenosides. Jeon et al. [31] reported the species difference in the gut metabolism and absorption of ginsenosides in the pathway from GRd to PPD and from GRe to PPT between mice and rats. The pharmacokinetic features of ginsenosides after repeated oral administration of RGE in humans were similar to those in mice rather than those in rats, i.e., GRb1, GRb2, GRc, GRd, GRg3, CK, PPD, and GRe were detected in mouse plasma, but GRb1, GRb2, GRc, GRd, PPD, and PPT were detected in rat plasma after the repeated oral administration of RGE [31]. In human plasma, GRb1, GRb2, GRc, GRd, GRg3, CK, PPD, and PPT were detected [34]. Moreover, the half-lives of GRg3, CK, and PPD in mice were similar to those in human subjects [31,34]. Based on these previous results, we selected mice as experimental animals in this study.

The specific Lactobacillus species, such as Lactobacillus sp., and Bifidobacterium sp., affect ginsenoside metabolism and are present in the intestine $[24,35,36,49]$. To further ascertain whether LAB affects the metabolism of ginsenoside, it is necessary to limit the LAB growth, which already exists in the body. Amoxicillin is a penicillin-based antibiotic that works extensively on bacterial infectious diseases and even a small dose of it limits the most of the lactobacillus growth influenced to the metabolism of ginsenoside [50-52]. Therefore, the study aimed to investigate the effects of LAB on the in vivo metabolism and pharmacokinetics of ginsenosides after the pretreatment of amoxicillin antibiotics in mice. 


\section{Materials and Methods}

\subsection{Materials}

RGE was purchased from the Punggi Ginseng Cooperative Association (Youngjoo, Kyungpook, Korea) (Table 1). 20(S)-ginsenosides Rb1 (GRb1), GRb2, GRc, GRd, GRg1, GRg3, GRe, GRh1, GRh2, GF1, GF2, 20(S)-compound K (CK), 20(S)-proptopanaxadiol (PPD), and 20(S)-protopanaxatriol (PPT) were purchased from the Ambo Institute (Daejeon, Korea). Hank's balanced salt solution (HBSS, pH 7.4), propranolol, caffeine, atenolol, ofloxacin, metformin, berberine (internal standards, IS), and pooled mouse plasma were purchased from Sigma-Aldrich Chemical Co. (St. Louis, MO, USA). Commercially available lactic acid bacterial formulation (LAB) was purchased from Chong Kun Dang Health Care (Dangjin-si, Chungcheongnam-do, Korea) (Table 2). Difco Lactobacilli MRS broth was purchased from BD BioSciences (Sparks, MD, USA). Collagen-coated 12-transwell, Dulbecco's modified eagle medium, phosphate-buffered saline (PBS), fecal bovine serum, non-essential amino acids, penicillin-streptomycin, pooled liver microsomes prepared from male CD-1 mice were purchased from Corning Life Sciences (Tewksbury, MA, USA). All other chemicals and solvents were of reagent or analytical grade.

Table 1. The content of ginsenoside in red ginseng extract (RGE).

\begin{tabular}{cccc}
\hline PPD-Type & Content $(\mathbf{m g} / \mathbf{g}$ RGE) & PPT-Type & Content (mg/g RGE) \\
\hline GRb1 & 4.7 & GRg3 & 3.5 \\
GRb2 & 2.3 & GRh2 & ND \\
GRc & 2.5 & CK & ND \\
GRd & 1.3 & PPD & ND \\
F2 & ND & Total content of PPD-type 14.3 mg/g RGE \\
\hline PPT-type & Content (mg/g RGE) & PPT-type & Content (mg/g RGE) \\
\hline GRe & 1.3 & GRh1 & 1.6 \\
GRg1 & 0.6 & F1 & ND \\
GRf & 1.1 & PPT & Total content of PPD-type 4.6 mg/g RGE \\
\cline { 2 - 4 } & & \multicolumn{2}{c}{}
\end{tabular}

Table 2. Strains contained in the commercially available lactic acid bacterial formulation (LAB).

\begin{tabular}{ccc}
\hline Species & Species & Species \\
\hline L. helveticus & L. rhamnosus & B. lactis \\
L. bulgaricus & L. casei & Enterococcus faecium \\
L. fermentum & L. reuteri & Enterococcus faecalis \\
L. gasseri & L. plantarum & Lactococcus lactis \\
L. paracasei & L. salivarius & Streptococcus thermophiles \\
L. acidophilus & B. longum & \\
B. breve & B. bifidum & Total 1 billion CFU $/ 2 \mathrm{~g}$ \\
\hline
\end{tabular}

\subsection{In Vitro RGE Fermentation Study with $L A B$}

For identifying the effects of LAB on ginsenoside metabolism, in vitro incubation study was preceded. Autoclaved RGE $(100 \mathrm{mg} / 10 \mathrm{~mL}$ in distilled water) and autoclaved MRS broth (550 mg/10 mL in distilled water) were mixed and added $2 \mathrm{~g}$ of LAB (contained 1 billion CFU). Then, the mixture was incubated for 8 days in a shaking incubator at 37 and $300 \mathrm{rpm}$. For the analysis of ginsenosides, $0.2 \mathrm{~mL}$ aliquot of incubation mixture was collected every $24 \mathrm{~h}$ for 7 days. The incubation medium was diluted 100 -fold with distilled water and stored at $-80^{\circ} \mathrm{C}$ for the analysis of ginsenosides using a liquid chromatographytandem mass spectrometry (LC-MS/MS) system. Microbial growth was determined by measuring the optical density at $600 \mathrm{~nm}\left(\mathrm{OD}_{600}\right)$ using UV spectrophotometry.

To compare the involvement of LAB on individual ginsenoside, an aliquot $(10 \mu \mathrm{L})$ of each ginsenoside stock solution $(10 \mathrm{mM}$ in methanol) was mixed with autoclaved MRS 
broth $(550 \mathrm{mg} / 10 \mathrm{~mL}$ in distilled water) and added $2 \mathrm{~g}$ of LAB (contained 1 billion CFU). Then, the mixture was incubated for 7 days in a shaking incubator at $37^{\circ} \mathrm{C}$ and $300 \mathrm{rpm}$. For the analysis of ginsenosides, $0.2 \mathrm{~mL}$ aliquot of incubation mixture was collected every $24 \mathrm{~h}$ for 7 days. The incubation medium was diluted 100-fold with distilled water and stored at $-80{ }^{\circ} \mathrm{C}$. For the ginsenoside analysis, $200 \mu \mathrm{L}$ of an IS solution $(0.05 \mathrm{ng} / \mathrm{mL}$ berberine in methanol) was added to $30 \mu \mathrm{L}$ of 100 -fold diluted samples. The mixture was vortexed for $15 \mathrm{~min}$ and centrifuged at $16,000 \times g$ for $5 \mathrm{~min}$. After centrifugation, a $2 \mu \mathrm{L}$ aliquot was injected into the LC-MS/MS system.

\subsection{Pharmacokinetic Study}

Male ICR mice (7-weeks-year-old, 30-35 g) were purchased from Samtako Co. (Osan, Kyunggi-do, Korea). Animals were acclimatized for 1 week in an animal facility at Kyungpook National University. Food and water were available ad libitum. The overall experimental scheme is shown in Figure 2.
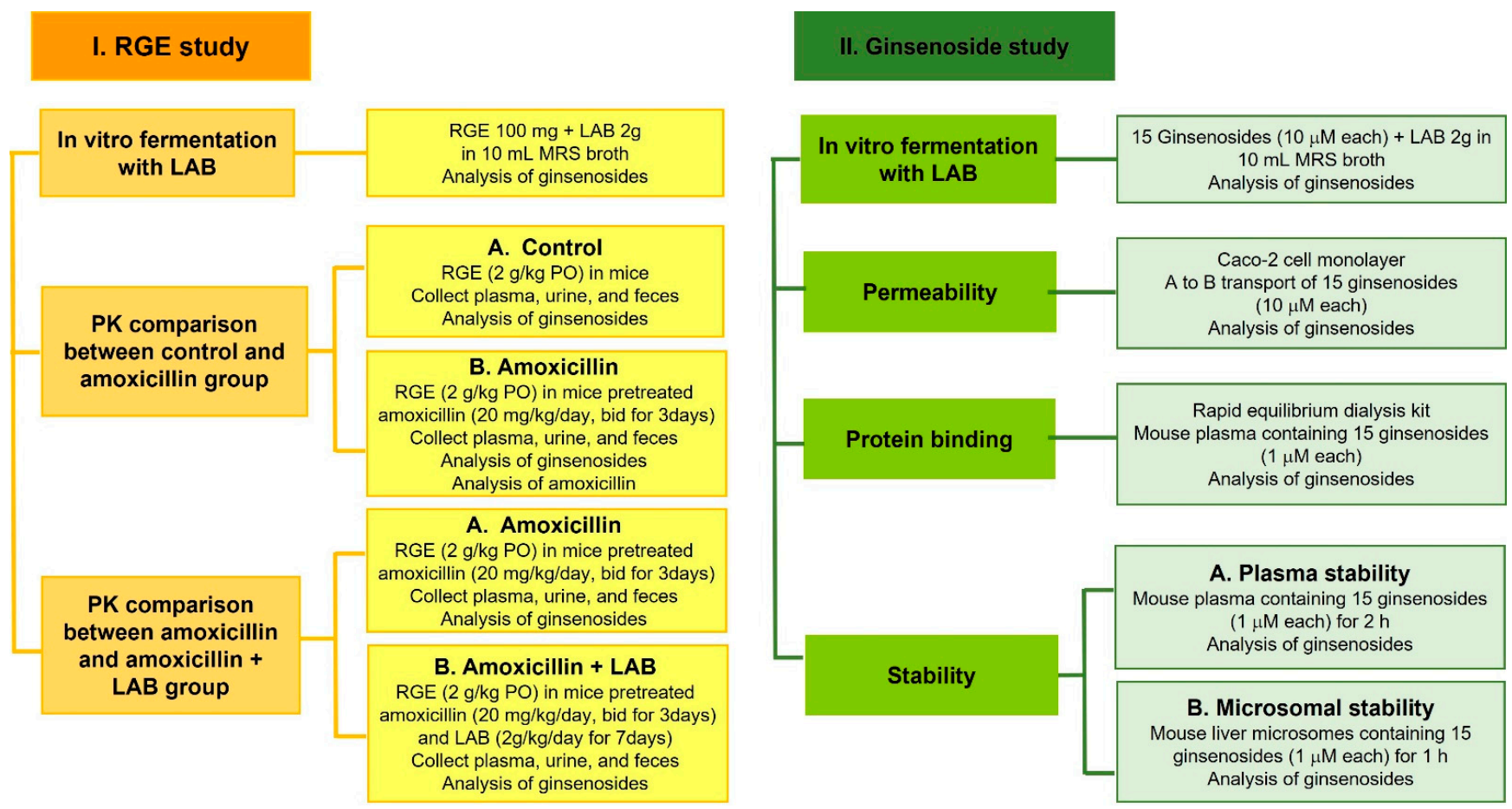

Figure 2. Overall experimental scheme for studies using RGE and 15 ginsenosides.

2.3.1. The Effect of Amoxicillin on the Intestinal Metabolism and the Pharmacokinetics of Ginsenosides

To investigate the effect of amoxicillin on the intestinal metabolism of ginsenosides, mice received amoxicillin $(n=9,20 \mathrm{mg} / \mathrm{kg} /$ day, dissolved in water at $2 \mathrm{~mL} / \mathrm{kg}$, twice daily) for 3 days via oral gavage. Before blood sampling, mice were anesthetized using isoflurane (isoflurane vaporizer to $2 \%$ with oxygen flow at $0.8 \mathrm{~L} / \mathrm{min}$ ) for $5 \mathrm{~min}$. Blood sampling was performed using a sparse sampling method via the right or left retro-orbital vein under isoflurane anesthesia at 24 and $48 \mathrm{~h}$ through the heparinized capillary tube (Heinz Herenz, Hamburg, Germany). The last blood sampling was performed via abdominal artery using a heparin-treated 1-mL syringe (Jung Lim Co. Ltd., Choong-Buk, Korea) under anesthesia with isoflurane at $72 \mathrm{~h}$ after the first dose of amoxicillin solution (time schedule and blood sampling volume are given in Table 3). After the centrifugation of the blood samples at $10,000 \times g$ for $1 \mathrm{~min}, 30 \mu \mathrm{L}$ aliquots of plasma were stored at $-80{ }^{\circ} \mathrm{C}$ for the analysis of plasma amoxicillin concentration. Aliquots $(200 \mu \mathrm{L})$ of an IS $(0.05 \mathrm{ng} / \mathrm{mL}$ berberine in acetonitrile) were added to $30 \mu \mathrm{L}$ of plasma samples. After that, the mixture was vortexed 
for $15 \mathrm{~min}$ and centrifuged at $16,000 \times g$ for $5 \mathrm{~min}$. After centrifugation, $200 \mu \mathrm{L}$ of the supernatant was transferred to a clean tube and dried under a nitrogen stream at $40{ }^{\circ} \mathrm{C}$. The residue was reconstituted using $100 \mu \mathrm{L}$ of $50 \%$ acetonitrile supplemented with $0.1 \%$ formic acid, and a 2- $\mu \mathrm{L}$ aliquot was injected into the LC-MS/MS system.

Table 3. Blood sampling method for the effect of amoxicillin on ginsenoside pharmacokinetics in mice.

\begin{tabular}{|c|c|c|c|c|c|c|c|}
\hline Group & \multicolumn{4}{|c|}{ Amoxicillin } & \multicolumn{3}{|c|}{ Control } \\
\hline $\begin{array}{l}\text { Sampling } \\
\text { Time (h) }\end{array}$ & $\begin{array}{c}\text { Group } 1 \\
(n=3)\end{array}$ & $\begin{array}{c}\text { Group } 2 \\
(n=3)\end{array}$ & $\begin{array}{c}\text { Group } 3 \\
(n=3)\end{array}$ & $\begin{array}{l}\text { Blood } \\
\text { Volume } \\
(\mu \mathrm{L})\end{array}$ & $\begin{array}{c}\text { Group } 4 \\
(n=3)\end{array}$ & $\begin{array}{c}\text { Group } 5 \\
(n=3)\end{array}$ & $\begin{array}{c}\text { Blood } \\
\text { Volume } \\
(\mu \mathrm{L})\end{array}$ \\
\hline 0 & & RO-right & & 80 & RO-right & & 80 \\
\hline 2 & & & RO-right & 80 & & RO-right & 80 \\
\hline 4 & & RO-left & & 80 & RO-left & & 80 \\
\hline 8 & & & RO-left & 80 & & RO-left & 80 \\
\hline 24 & RO-right & AA & & 100 & AA & & 100 \\
\hline 48 & RO-left & & AA & 100 & & AA & 100 \\
\hline 72 & AA & & & 100 & & & \\
\hline
\end{tabular}

RO-right: retro-orbital blood sampling-right eye under anesthesia with isoflurane. RO-left: retro-orbital blood sampling-left eye under anesthesia with isoflurane. AA: abdominal artery blood sampling under anesthesia with isoflurane.

Among the amoxicillin treated mice, six mice received RGE in a single dose $(2 \mathrm{~g} / \mathrm{kg}$ suspended in water at $2 \mathrm{~mL} / \mathrm{kg}$ ) via oral gavage $2 \mathrm{~h}$ after the last amoxicillin administration on 4th day and then returned to their metabolic cages with food and water ad libitum and urine and feces samples were collected for $48 \mathrm{~h}$. The urine and feces samples were weighed, and $30 \mu \mathrm{L}$ aliquots of urine and $100 \mu \mathrm{L}$ aliquots of $10 \%$ feces homogenates were stored at $-80{ }^{\circ} \mathrm{C}$ until the analysis of the ginsenosides. Blood sampling was performed using a sparse sampling method via the right or left retro-orbital vein under anesthesia with isoflurane at $0,2,4$, and $8 \mathrm{~h}$ after the RGE administration through the heparinized capillary tube. The last blood sampling was performed via abdominal artery using a heparin-treated 1-mL syringe under isoflurane anesthesia at 24 and $48 \mathrm{~h}$ after the RGE administration (time schedule and blood sampling volume was given in Table 3). After the centrifugation of the blood samples at $10,000 \times g$ for $1 \mathrm{~min}, 30-\mu \mathrm{L}$ aliquots of plasma were stored at $-80^{\circ} \mathrm{C}$ until the analysis of the ginsenosides. For the comparison, six mice received water $(2 \mathrm{~mL} / \mathrm{kg})$ via oral gavage for 3 days and, on 4 th day, mice received RGE in a single dose $(2 \mathrm{~g} / \mathrm{kg}$ suspended in water at $2 \mathrm{~mL} / \mathrm{kg}$ ) via oral gavage $2 \mathrm{~h}$ after the last water administration and then returned to their metabolic cages with food and water ad libitum and urine and feces samples were collected for $48 \mathrm{~h}$.

Aliquots $(200 \mu \mathrm{L})$ of an IS $(0.05 \mathrm{ng} / \mathrm{mL}$ berberine in methanol) were added to $30 \mu \mathrm{L}$ of plasma or urine samples. Aliquots $(600 \mu \mathrm{L})$ of an IS methanol solution containing 0.05 $\mathrm{ng} / \mathrm{mL}$ berberine were added to $100 \mu \mathrm{L}$ of $10 \%$ feces homogenate samples. After that, the mixture was vortexed for $15 \mathrm{~min}$ and centrifuged at $16,000 \times \mathrm{g}$ for $5 \mathrm{~min}$. After centrifugation, $200 \mu \mathrm{L}$ of the supernatant was transferred to a clean tube and dried under a nitrogen stream at $40{ }^{\circ} \mathrm{C}$. The residue was reconstituted using $100 \mu \mathrm{L}$ of $70 \%$ methanol supplemented with $0.1 \%$ formic acid, and a $10-\mu \mathrm{L}$ aliquot was injected into the LC-MS/MS system.

2.3.2. The Effect of LAB Supplementation on the Pharmacokinetics of Ginsenosides in Amoxicillin Treated Mice

Mice received amoxicillin $(n=12,20 \mathrm{mg} / \mathrm{kg}$, dissolved in water at $2 \mathrm{~mL} / \mathrm{kg}$, twice daily) for 3 days via oral gavage. From the 4 th day, mice from the LAB + amoxicillin treatment group received LAB ( $2 \mathrm{~g} / \mathrm{kg}$ suspended in water at $2 \mathrm{~mL} / \mathrm{kg}$, once daily) for 7 days via oral gavage. Mice from the amoxicillin treatment group received water $(2 \mathrm{~mL} / \mathrm{kg}$, once daily) for 7 days via oral gavage. Subsequently, on the 10th day, mice received RGE in a single dose $(2 \mathrm{~g} / \mathrm{kg}$ suspended in water at $2 \mathrm{~mL} / \mathrm{kg})$ via oral gavage $2 \mathrm{~h}$ after the last LAB 
or water administration and then returned to their metabolic cages with food and water ad libitum and urine and feces samples were collected for $48 \mathrm{~h}$. The urine and feces samples were weighed, and $30 \mu \mathrm{L}$ aliquots of urine and $100 \mu \mathrm{L}$ aliquots of $10 \%$ feces homogenates were stored at $-80{ }^{\circ} \mathrm{C}$ until the analysis of the ginsenosides.

Blood sampling was performed using a sparse sampling method via the right or left retro-orbital vein under isoflurane anesthesia at $0,2,4$, and $8 \mathrm{~h}$ after the RGE administration through the heparinized capillary tube. The last blood sampling was performed via abdominal artery using heparin-treated $1 \mathrm{~mL}$ syringe under isoflurane anesthesia at 24 and $48 \mathrm{~h}$ after the RGE administration (time schedule and blood sampling volume was given in Table 4). After centrifugation of the blood samples at $10,000 \times g$ for $1 \mathrm{~min}, 30 \mu \mathrm{L}$ aliquots of plasma were stored at $-80^{\circ} \mathrm{C}$ until the analysis of the ginsenosides. Subsequent protocols were identical to the amoxicillin treated group.

Table 4. Blood sampling method for the effect of LAB on ginsenoside pharmacokinetic study in mice.

\begin{tabular}{ccccccc}
\hline Group & \multicolumn{3}{c}{ Amoxicillin + LAB } & \multicolumn{3}{c}{ Amoxicillin } \\
\hline $\begin{array}{c}\text { Sampling } \\
\text { Time (h) }\end{array}$ & $\begin{array}{c}\text { Group 1 } \\
(n=3)\end{array}$ & $\begin{array}{c}\text { Group 2 } \\
(n=3)\end{array}$ & $\begin{array}{c}\text { Blood } \\
\text { Volume } \\
(\mu \mathrm{L})\end{array}$ & $\begin{array}{c}\text { Group 3 } \\
(n=3)\end{array}$ & $\begin{array}{c}\text { Group 4 } \\
(n=3)\end{array}$ & $\begin{array}{c}\text { Blood } \\
\text { Volume } \\
(\mu \mathrm{L})\end{array}$ \\
\hline 0 & RO-right & & 80 & RO-right & & 80 \\
2 & & RO-right & 80 & & RO-right & 80 \\
4 & RO-left & RO-left & 80 & RO-left & & 80 \\
8 & AA & AA & 100 & AA & RO-left & 80 \\
24 & & AA & AA & 100 \\
48 & & & & & & \\
\hline
\end{tabular}

RO-right: retro-orbital blood sampling-right eye under anesthesia with isoflurane. RO-left: retro-orbital blood sampling-left eye under anesthesia with isoflurane. AA: abdominal artery blood sampling under anesthesia with isoflurane.

\subsection{Plasma Protein Binding of Ginsenosides}

The protein binding of 15 ginsenosides, GRb1, GRb2, GRc, GRd, GRe, GRf, GRg1, GRg3, GRh1, GRh2, GF1, GF2, CK, PPD, and PPT (1 $\mu \mathrm{M}$ each), in pooled mouse plasma (purchased from Sigma-Aldrich, St. Louis, MO, USA) was determined using a rapid equilibrium dialysis kit (ThermoFisher Scientific Korea, Seoul, Korea) according to the manufacturer's instructions. Briefly, $100 \mu \mathrm{L}$ of mouse plasma containing $1 \mu \mathrm{M}$ of each ginsenoside was added to the semipermeable membrane's inner sample chamber (molecular weight cut-off $8000 \mathrm{Da}$ ), and $300 \mu \mathrm{L}$ of PBS was added to the outer buffer chamber. The samples were then incubated for $4 \mathrm{~h}$ at $37^{\circ} \mathrm{C}$ on a shaking incubator at $300 \mathrm{rpm}$, followed by collecting $30-\mu \mathrm{L}$ aliquots from both the sample and buffer chambers. Samples were mixed with equal volumes of fresh PBS or blank mouse plasma to match the sample matrices and aliquots $(200 \mu \mathrm{L})$ of an IS $(0.05 \mathrm{ng} / \mathrm{mL}$ berberine in methanol) were added to $60 \mu \mathrm{L}$ of matrix matched samples. The mixture was vortexed for $15 \mathrm{~min}$ and centrifuged at $16,000 \times g$ for $5 \mathrm{~min}$. After centrifugation, a $2 \mu \mathrm{L}$ aliquot was injected into the LC-MS/MS system to analyze ginsenoside concentration.

Positive control study using atenolol (for low protein binding) and propranolol (for high protein binding) was also performed. A $100 \mu \mathrm{L}$ aliquot of mouse plasma containing $1 \mu \mathrm{M}$ of atenolol or propranolol was added to sample chamber and $300 \mu \mathrm{L}$ of PBS was added to the outer buffer chamber. Subsequent protocols were identical to the method described above except for the use of ice-cold IS solution $(200 \mu \mathrm{L} ; 0.05 \mathrm{ng} / \mathrm{mL}$ berberine in acetonitrile) to $30 \mu \mathrm{L}$ of the reaction samples.

\subsection{Plasma and Microsomal Stability of Ginsenoside}

The plasma stability of 15 ginsenosides, GRb1, GRb2, GRc, GRd, GRe, GRf, GRg1, GRg3, GRh1, GRh2, GF1, GF2, CK, PPD, and PPT (1 $\mu \mathrm{M}$ each), in pooled mouse plasma (purchased from Sigma-Aldrich, St. Louis, MO, USA) and in pooled liver microsomes prepared from male CD-1 mice (Corning Life Sciences; Tewksbury, MA, USA) was determined. 
For plasma stability, $100 \mu \mathrm{L}$ of mouse plasma containing $1 \mu \mathrm{M}$ of each ginsenoside was incubated for $2 \mathrm{~h}$ at $37^{\circ} \mathrm{C}$ on a shaking incubator at $300 \mathrm{rpm}$, this followed by collecting $30-\mu \mathrm{L}$ aliquots from the incubation tubes. The reaction was quenched by addition of an ice-cold IS solution $(200 \mu \mathrm{L} ; 0.05 \mathrm{ng} / \mathrm{mL}$ berberine in methanol) to $30 \mu \mathrm{L}$ of plasma samples. Thereafter, the mixture was vortexed for $15 \mathrm{~min}$ and centrifuged at $16,000 \times g$ for $5 \mathrm{~min}$. After centrifugation, a $2-\mu \mathrm{L}$ aliquot was injected into the LC-MS/MS system.

For microsomal stability, individual ginsenoside $(1 \mu \mathrm{M}$ each) was reconstituted in $100 \mathrm{mM}$ potassium phosphate buffer ( $\mathrm{pH} 7.4$ ) containing $0.25 \mathrm{mg}$ of mouse liver microsomes and preincubated for $5 \mathrm{~min}$ at $37^{\circ} \mathrm{C}$. This reaction was initiated by adding an NADPHgenerating system (1.3 mM $\beta$-NADP, $3.3 \mathrm{mM}$ glucose-6-phosphate, $3.3 \mathrm{mM} \mathrm{MgCl}$, and 1.0 unit/mL glucose-6-phosphate dehydrogenase; purchased form Corning Life Sciences) (to make final volume of $100 \mu \mathrm{L}$ ). The reaction mixture was incubated for $1 \mathrm{~h}$ at $37^{\circ} \mathrm{C}$ in a shaking water bath and the reaction was quenched by addition of addition of an ice-cold IS solution ( $200 \mu \mathrm{L} ; 0.05 \mathrm{ng} / \mathrm{mL}$ berberine in methanol) to $30 \mu \mathrm{L}$ of the reaction samples. The mixture was vortexed for $15 \mathrm{~min}$ and centrifuged at $16,000 \times g$ for $5 \mathrm{~min}$. After centrifugation, a $2 \mu \mathrm{L}$ aliquot was injected into the LC-MS/MS system.

Positive control study using $1 \mu \mathrm{M}$ metformin (for high microsomal stability) and $1 \mu \mathrm{M}$ propranolol (for low microsomal stability) was also performed to ensure the system feasibility. Subsequent protocols were identical to the method described above except for the use of ice-cold IS solution ( $200 \mu \mathrm{L} ; 0.05 \mathrm{ng} / \mathrm{mL}$ berberine in acetonitrile) to $30 \mu \mathrm{L}$ of the reaction samples.

\subsection{Caco-2 Permeability of Ginsenoside}

Caco-2 cells (passage no 41-43; purchased from ATCC, Rockville, MD, USA) were grown in tissue culture flasks containing Dulbecco's modified eagle medium supplemented with $20 \%$ fecal bovine serum, $1 \%$ non-essential amino acids, and $1 \%$ penicillin-streptomycin. Caco-2 cells were seeded on collagen-coated 12-transwell membranes at a density of $5 \times$ $10^{5}$ cells $/ \mathrm{mL}$ and maintained at $37^{\circ} \mathrm{C}$ in a humidified atmosphere with $5 \% \mathrm{CO}_{2} / 95 \%$ air for 21 days. The culture medium was replaced every other day. On the day of the experiment, the growth medium was discarded, and the attached cells were washed with prewarmed HBSS ( $\mathrm{pH} 7.4$ ) and preincubated with HBSS for 20 min at $37^{\circ} \mathrm{C}$, and the permeability assay was conducted as previously described [53]. Briefly, to measure the apical to basal permeability of each ginsenoside, $0.5 \mathrm{~mL}$ of HBSS containing $50 \mu \mathrm{M}$ of individual ginsenoside (GRb1, GRb2, GRc, GRd, GRe, GRf, GRg1, GRg3, GRh1, GRh2, GF1, GF2, CK, PPD, or PPT) was added to the apical side (inside of the insert) and $1.5 \mathrm{~mL}$ of fresh HBSS was added to the basal side of the insert. The insert was transferred to a well containing $1.5 \mathrm{~mL}$ of fresh HBSS every $15 \mathrm{~min}$ for $1 \mathrm{~h}$. Aliquots $(0.1 \mathrm{~mL})$ in basal side were transferred to clean tubes and stored at $-80^{\circ} \mathrm{C}$ until further analysis. Transport study was performed for $1 \mathrm{~h}$ based on the linearity of the cumulative transport amounts of ginsenosides against the transport time. The integrity of cell monolayers was evaluated before and after the permeability experiments by measuring the transepithelial electrical resistance (TEER) values using an epithelial volt/ohm meter (World Precision Instruments; Sarasota, FL, USA).

To confirm the feasibility of Caco-2 permeability study from apical to basal direction, four permeability marker compounds such as caffeine and propranolol (for high permeability), ofloxacin (for moderate permeability), and atenolol (for low permeability) were used [54]. Briefly, $0.5 \mathrm{~mL}$ of HBSS containing the mixture of $2 \mu \mathrm{M}$ caffeine, $2 \mu \mathrm{M}$ propranolol, $10 \mu \mathrm{M}$ ofloxacin, and $50 \mu \mathrm{M}$ atenolol was added to the apical side and $1.5 \mathrm{~mL}$ of fresh HBSS without marker compounds were added to basal side of the insert. Every $15 \mathrm{~min}$, the insert was transferred to a well containing $1.5 \mathrm{~mL}$ of fresh HBSS for $1 \mathrm{~h}$. Aliquots $(0.2 \mathrm{~mL})$ in basal side were transferred to clean tubes and stored at $-80^{\circ} \mathrm{C}$. For the analysis of these compounds, the thawed $200-\mu \mathrm{L}$ samples were extracted using $200 \mu \mathrm{L}$ of acetonitrile containing $0.05 \mathrm{ng} / \mathrm{mL}$ berberine (IS) and vigorous mixing for $10 \mathrm{~min}$ followed by sonication 
for $5 \mathrm{~min}$ and centrifugation at $16,000 \times g$ for $5 \mathrm{~min}$ at $4{ }^{\circ} \mathrm{C}$. After centrifugation, an aliquot $(2 \mu \mathrm{L})$ was injected into an LC-MS/MS.

\subsection{LC-MS/MS Analysis}

The concentrations of amoxicillin in the mouse plasma samples were analyzed using an Agilent 6470 triple quadrupole LC-MS/MS system (Agilent, Wilmington, DE, USA). Amoxicillin peaks were separated on a Polar RP column $(150 \times 2.0 \mathrm{~mm}, 4.0 \mu \mathrm{m}$ particle size; Phenomenex, Torrance, CA, USA) with mobile phase $50 \%$ acetonitrile supplemented with $0.1 \%$ formic acid at a flow rate of $0.3 \mathrm{~mL} / \mathrm{min}$. Quantification was performed using multiple reaction monitoring (MRM) mode at $\mathrm{m} / \mathrm{z} 366.3 \rightarrow 114.0$ for amoxicillin (collision energy (CE) of $20 \mathrm{eV}$, retention time ( $\mathrm{T}_{\mathrm{R}}$ ) of $2.5 \mathrm{~min}$ ) and $\mathrm{m} / \mathrm{z} 336.0320 .0$ for berberin (IS) (CE $30 \mathrm{eV}, \mathrm{T}_{\mathrm{R}} 4.6 \mathrm{~min}$ ) in the positive ion mode. The standard calibration curve for amoxicillin was linear in the concentration range of $2-5000 \mathrm{ng} / \mathrm{mL}$ for the plasma samples, and the interday and intraday precision and accuracy were $<15 \%$.

The concentrations of caffeine, propranolol, ofloxacin, atenolol, and metformin, in the samples were measured simultaneously using an Agilent 6470 Triple Quadrupole LCMS/MS system with a slight modification of the method of Song et al. [53-56]. Separation was performed on a Luna CN column $(2.0 \mathrm{~mm} \times 150 \mathrm{~mm}, 5 \mu \mathrm{m}$; Phenomenex, Torrance, CA, USA) with mobile phase $50 \%$ acetonitrile supplemented with $0.1 \%$ formic acid at a flow rate of $0.2 \mathrm{~mL} / \mathrm{min}$. Quantification was carried out using MRM mode at $\mathrm{m} / \mathrm{z} 195 \rightarrow 138$ for caffeine (CE $\left.15 \mathrm{eV}, \mathrm{T}_{\mathrm{R}} 2.4 \mathrm{~min}\right), \mathrm{m} / \mathrm{z} 260 \rightarrow 116$ for propranolol (CE $10 \mathrm{eV}, \mathrm{T}_{\mathrm{R}} 3.2 \mathrm{~min}$ ), $\mathrm{m} / \mathrm{z} 267 \rightarrow 145$ for atenolol (CE $25 \mathrm{eV}, \mathrm{T}_{\mathrm{R}} 2.3 \mathrm{~min}$ ), $\mathrm{m} / \mathrm{z} 362 \rightarrow 318$ for ofloxacin (CE $15 \mathrm{eV}$, $\mathrm{T}_{\mathrm{R}} 2.6 \mathrm{~min}$ ), $m / z 130 \rightarrow 71$ for metformin ( $\mathrm{CE} 20 \mathrm{eV}, \mathrm{T}_{\mathrm{R}} 2.2 \mathrm{~min}$ ), and $m / z 336.0 \rightarrow 320.0$ for berberin (IS) (CE $30 \mathrm{eV}, \mathrm{T}_{\mathrm{R}} 4.6 \mathrm{~min}$ ) in the positive ionization mode.

The concentrations of ginsenosides were analyzed using a modified LC-MS/MS method $[30,57]$ using an Agilent 6470 triple quadrupole LC-MS/MS system (Agilent, Wilmington, DE, USA). The ginsenosides were separated on a Polar RP column $(150 \times 2.0 \mathrm{~mm}$, $4.0 \mu \mathrm{m}$ particle size) (Phenomenex, Torrance, CA, USA) with a mobile phase consisting of $0.1 \%$ formic acid in water (phase A) and $0.1 \%$ formic acid in methanol (phase B) at a flow rate of $0.3 \mathrm{~mL} / \mathrm{min}$. The gradient elution used was $70 \%$ of phase $B$ for $0-0.2 \mathrm{~min}, 70-90 \%$ (phase B) for 0.2-1.0 min, 90\% (phase B) for 1.0-6.5 min, 90-70\% (phase B) for 6.5-7.0 min, and $70 \%$ (phase B) for 7.0-10.0 min. Quantification was performed using MRM mode in the positive ion mode, according to the previously published methods [30,34,57,58]: $\mathrm{m} / \mathrm{z}$ $1131.6 \rightarrow 365.1$ for GRb1 (CE $65 \mathrm{eV}, \mathrm{T}_{\mathrm{R}} 3.4 \mathrm{~min}$ ), $\mathrm{m} / z$ 1101.6 $\rightarrow 335.1$ for GRb2 and GRc (CE $60 \mathrm{eV}, \mathrm{T}_{\mathrm{R}} 4.2$ and $\left.3.2 \mathrm{~min}\right), \mathrm{m} / \mathrm{z} 969.9 \rightarrow 789.5$ for GRd and GRe (CE $50 \mathrm{eV}, \mathrm{T}_{\mathrm{R}} 4.8$ and $1.7 \mathrm{~min}$ ), $m / z 823.5 \rightarrow 365.1$ for GRf (CE $55 \mathrm{eV}, \mathrm{T}_{\mathrm{R}} 3.2 \mathrm{~min}$ ), $\mathrm{m} / z$ 824.0 $\rightarrow 643.6$ for GRg1 (CE $40 \mathrm{eV}$, $\mathrm{T}_{\mathrm{R}} 1.8 \mathrm{~min}$ ), $\mathrm{m} / \mathrm{z} 807.5 \rightarrow 627.5$ for GF2 (CE $40 \mathrm{eV}, \mathrm{T}_{\mathrm{R}} 5.9 \mathrm{~min}$ ), $\mathrm{m} / \mathrm{z} 807.5 \rightarrow 365.2$ for GRg3 (CE $60 \mathrm{eV}, \mathrm{T}_{\mathrm{R}} 5.8 \mathrm{~min}$ ), $\mathrm{m} / \mathrm{z} 661.5 \rightarrow 203.1$ for GF1 (CE $40 \mathrm{eV}, \mathrm{T}_{\mathrm{R}} 3.7 \mathrm{~min}$ ), $\mathrm{m} / z$ 603.4 $\rightarrow 423.4$ for GRh1 (CE $10 \mathrm{eV}, \mathrm{T}_{\mathrm{R}} 3.2 \mathrm{~min}$ ), $\mathrm{m} / \mathrm{z} 587.4 \rightarrow 407.4$ for GRh2 (CE $15 \mathrm{eV}, \mathrm{T}_{\mathrm{R}} 6.6 \mathrm{~min}$ ), m/z $645.5 \rightarrow 203.1$ for CK (CE $35 \mathrm{eV}, \mathrm{T}_{\mathrm{R}} 6.6 \mathrm{~min}$ ), $\mathrm{m} / \mathrm{z} 425.3 \rightarrow 109.1$ for PPT (CE $30 \mathrm{eV}, \mathrm{T}_{\mathrm{R}} 5.4 \mathrm{~min}$ ), $\mathrm{m} / \mathrm{z} 411.3 \rightarrow 109.1$ for PPD (CE $25 \mathrm{eV}, \mathrm{T}_{\mathrm{R}} 7.3 \mathrm{~min}$ ), and $\mathrm{m} / \mathrm{z} 336.0 \rightarrow 320.0$ for berberin (IS) (CE $30 \mathrm{eV}, \mathrm{T}_{\mathrm{R}} 3.5 \mathrm{~min}$ ). For the 15 ginsenosides, the standard calibration curve for the mixture was linear in the concentration range of $0.5-200 \mathrm{ng} / \mathrm{mL}$, and the inter-day and intra-day precision and accuracy for 15 ginsenosides were $<15 \%$.

Berberine was selected as a common IS in this study because berberine showed stable and sensitive peaks after the protein precipitation method using either acetonitrile or methanol for the simultaneous analysis of wide range of ginsenosides, permeability marker compounds, as well as 15 probe substrates and metabolites for drug metabolizing enzymes or transporters $[30,57,59]$.

\subsection{Data Analysis}

Pharmacokinetic parameters were calculated using WinNonlin (version 5.1, Pharsight, Mountain View, CA, USA) by a non-compartmental analysis. 
Plasma protein binding was calculated using the following equation $[31,60]$ :

$$
\text { Plasma protein binding }=\left(1-\frac{\text { Drug concentration in buffer chamber }}{\text { Drug concentration in plasma sample chamber }}\right) \times 100(\%) \text {. }
$$

Plasma and microsomal stability was determined from the percent of remaining concentration of ginsenosides or marker compounds compared to their initial concentration $[53,61]$.

For the permeability calculation, the transport rate of ginsenosides and marker conpounds was calculated from the slope of the regression line from the mean permeated amounts vs. incubation time plot. The apparent permeability $\left(\mathrm{P}_{\text {app }}\right)$ was calculated from the following equation [54,62]:

$$
\operatorname{Papp}\left(10^{-6} \mathrm{~cm} / \mathrm{s}\right)=\frac{\text { transport rate }(\mathrm{nmol} / \mathrm{min})}{\text { concentration }(\mu \mathrm{M}) \times \operatorname{area}\left(\mathrm{cm}^{2}\right) \times 60 \mathrm{~s}} .
$$

The data are expressed as the means \pm standard deviation for the groups. Statistical analysis was performed using the Student $t$-test.

\section{Results}

\subsection{LAB-Mediated Ginsenosides Metabolism}

To ensure the metabolic activity of LAB about ginsenosides, we conducted a fermentation test of RGE with LAB in vitro. Some ginsenoside metabolites, such as CK, PPD, and PPT, which are not contained in natural RGE and final metabolites of ginsenosides, were significantly increased after incubating with LAB (Figure 3A,C). GRh1 and GRg3 also increased about $30 \%$ by fermentation with LAB for 7 days and the apparent amount of GRh2 remained unchanged (Figure 3A). Other intermediate metabolites, GRd, GF2, GRg1, and GRf, showed a gradual decrease by fermentation with LAB for 7 days. GRb1, GRb2, GRc, and GRe that are tetraglycosylated PPD-type or triglycosylated PPT-type ginsenoside, and GF1, which is an intermediate metabolite of PPT-type ginsenoside, showed the most significant decrease during the LAB fermentation process (Figure $3 \mathrm{~A}, \mathrm{~B}$ ). The results suggested that the metabolic activity of PPD-type and PPT-type ginsenosides by incubation with LAB may be different depending on the number of sugar moiety and glycosylated status. Microbial growth was stably maintained for the incubation period (7 days) (Figure 3D).

\subsection{Effect of Amoxicillin on the Metabolism of Ginsenoside}

To investigate the effect of amoxicillin on the pharmacokinetics and metabolism of ginsenosides, we orally administered RGE $(2 \mathrm{~g} / \mathrm{kg})$ in mice following repeated administration of amoxicillin. It is reported that the concentration of amoxicillin of at least $0.25 \mu \mathrm{g} / \mathrm{mL}$ to a maximum of $2 \mu \mathrm{g} / \mathrm{mL}$ must be maintained to inhibit the growth of LAB [50]. Thus, we verified the amoxicillin concentration in plasma following repeated administration of amoxicillin for three days to ensure the inhibitory effect of amoxicillin on LAB (Figure 4A). The concentration was maintained in the range of $0.9-1.8 \mu \mathrm{g} / \mathrm{mL}$ at 24,48 , and $72 \mathrm{~h}$ after the beginning of amoxicillin treatment, which was thought to be enough to impede the growth of LAB (Figure 4B). 

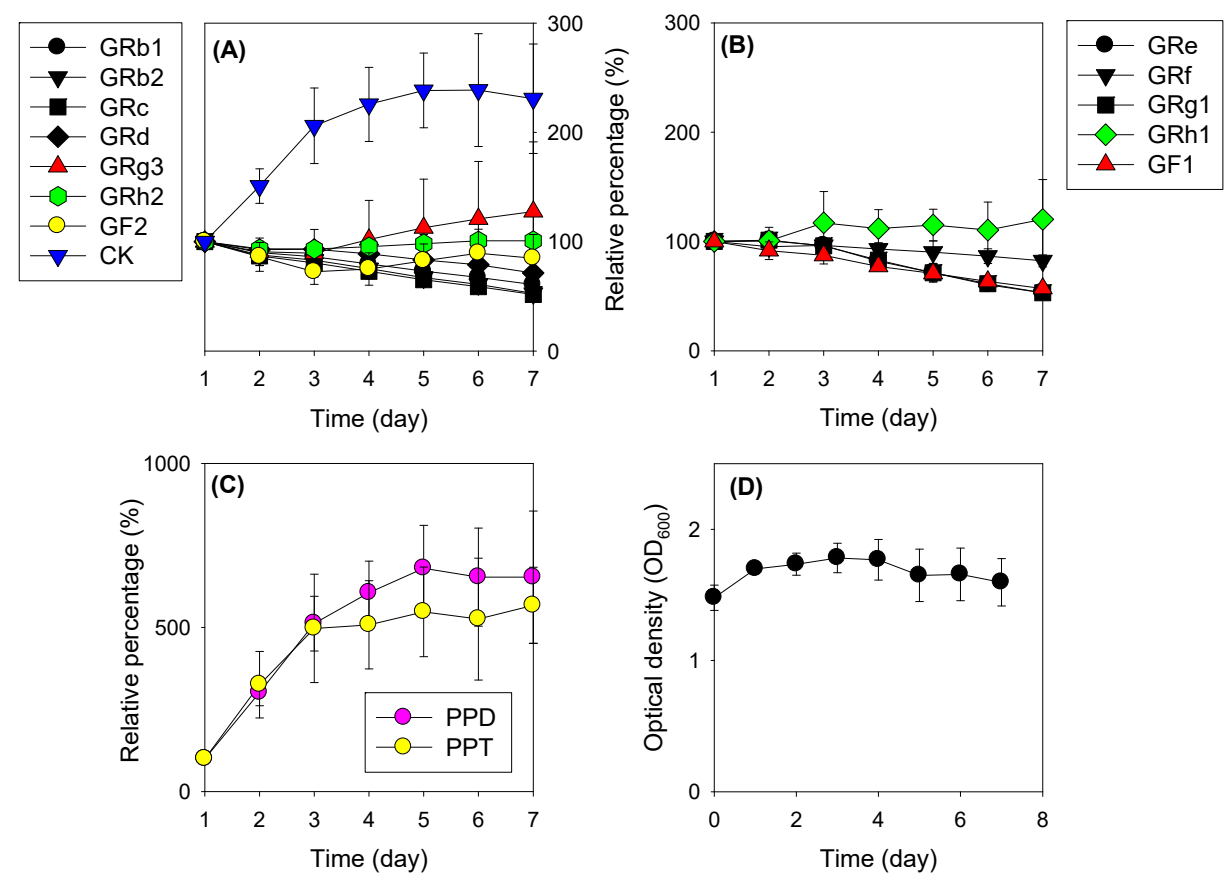

Figure 3. Alterations of 15 ginsenosides following the incubation of RGE with LAB for 7 days were expressed as the relative percentage of ginsenoside on the first day. (A) PPD-type ginsenosides except for final metabolite PPD; (B) PPT-type ginsenosides except for final metabolite PPT; (C) final metabolite ginsenosides PPD and PPT; (D) Optical density at $600 \mathrm{~nm}\left(\mathrm{OD}_{600}\right)$ of the MRS broth incubating RGE with LAB for 7 days. Data point represents the mean \pm standard deviation $(n=3)$.

(A)

Control

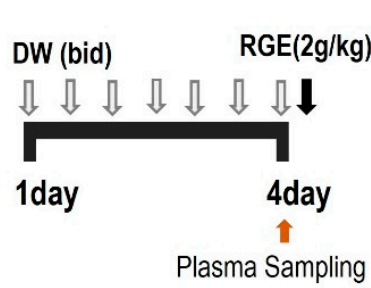

Amoxicillin

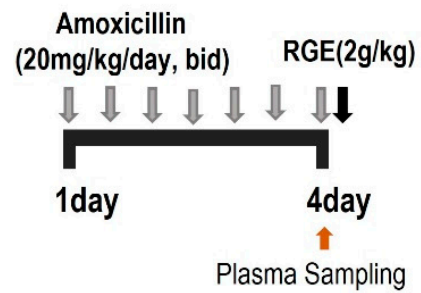

(B)

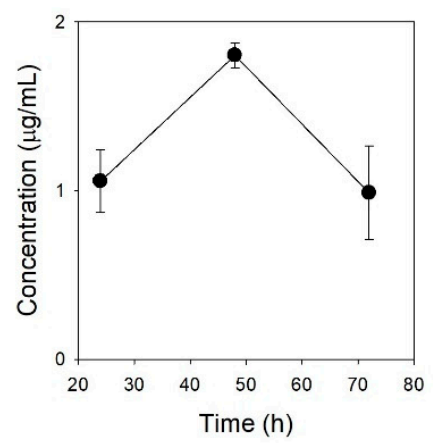

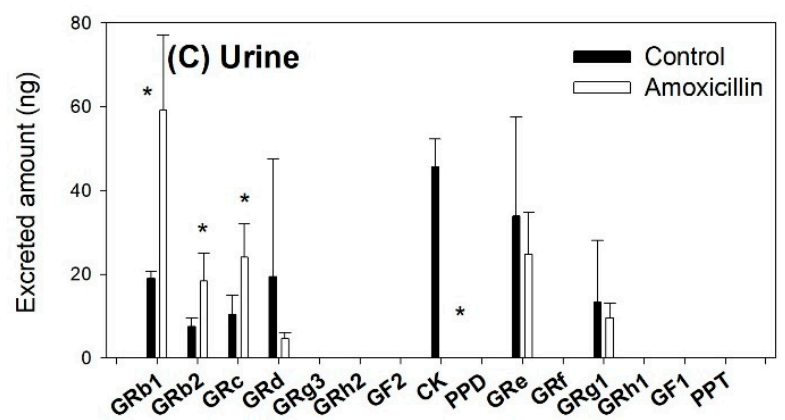

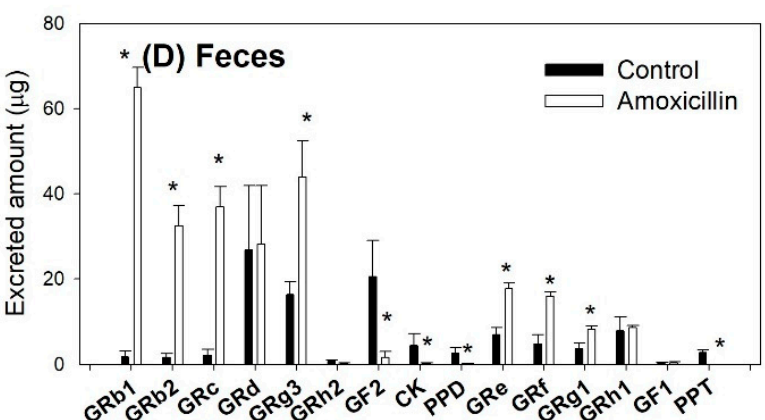

Figure 4. (A) Dosing schedule for repeated oral administration of amoxicillin $(20 \mathrm{mg} / \mathrm{kg} /$ day $)$ and a single oral administration of RGE (2 g/kg). DW: distilled water; bid: twice a day. (B) Plasma amoxicillin concentrations after repeated oral administration of amoxicillin for 3 days. Recovery of ginsenosides from (C) urine and (D) feces for $48 \mathrm{~h}$ in mice following a single oral administration of RGE $(2 \mathrm{~g} / \mathrm{kg})$ after repeated oral administration of amoxicillin for 3 days. The data point represents the mean \pm standard deviation $(n=3) .{ }^{*} p<0.05$ compared with control group. 
During this time, the recovery of ginsenosides from the urine and feces for $48 \mathrm{~h}$ was monitored (Figure 4C). The urinary recovery of all detected ginsenosides was much lower than the fecal recovery, which is attributed to the low oral absorption of ginsenosides and their elimination route. That is, the fecal recovery showed the sum of the absorbed and unabsorbed ginsenosides following oral intake of RGE. Additionally, several ginsenosides are reported to favor biliary excretion than renal excretion [7,31,37]. Compared to several ginsenosides identified in urine (i.e., GRb1, GRb2, GRc, GRd, CK, GRe, and GRg1), 15 ginsenosides were detected in feces (Figure 4C,D). By the amoxicillin treatment, trior tetraglycosylated ginsenosides (i.e., GRb1, GRb2, GRc, GRg3, GRe, GRf, and GRg1) were increased, whereas mono- or deglycosylated ginsenosides (i.e., F2, CK, PPD, and PPT) were significantly decreased (Figure 4D). These results suggested that the ginsenoside metabolism mediated the gut microbiota seemed to be significantly inhibited by the amoxicillin treatment since antibiotics could inhibit gut microbiota.

\subsection{Plasma Concentrations of Ginsenosides Following Single Administration of RGE after Repeated Administration of Amoxicillin}

Subsequently, we measured plasma ginsenosides concentrations following repeated administration of amoxicillin, and the pharmacokinetic parameters were compared between control and amoxicillin treatment (Figure 5 and Table 5). Plasma concentrations of $\mathrm{Rb} 1, \mathrm{Rb} 2$, and Rc were not significantly affected by the amoxicillin treatment compared to the control group. However, the plasma concentrations and $\mathrm{C}_{\max }$ value of $\mathrm{Rd}$ were decreased in the amoxicillin group compared to the control group (Figure 5 and Table 5), suggesting the decrease of $\mathrm{Rd}$ formation in the intestine mediated by intestinal microbiota because of the amoxicillin treatment. Ginsenosides CK, PPD, and PPT, which are not found in natural RGE, and final metabolites of ginsenosides, were detected in the control group. However, they were not seen in the plasma samples from the amoxicillin treatment group (Figure 5). The results suggested that the formation of CK, PPD, and PPT was blocked by the amoxicillin treatment.

Table 5. Pharmacokinetic parameters of ginsenosides in mouse after single dosing RGE with or without amoxicillin treatment.

\begin{tabular}{|c|c|c|c|c|c|}
\hline \multirow[b]{2}{*}{ Ginsenosides } & \multicolumn{5}{|c|}{ Control } \\
\hline & $\begin{array}{c}\text { AUC } \\
\text { (ng/mL·h) }\end{array}$ & $\underset{(\mathrm{ng} / \mathrm{mL})}{\mathrm{C}_{\max }}$ & $\mathrm{T}_{\max }(\mathrm{h})$ & MRT (h) & Half-Life (h) \\
\hline GRb1 & $895.9 \pm 81.3$ & $41.3 \pm 14.3$ & $8.0 \pm 0.0$ & $16.3 \pm 2.7$ & $25.9 \pm 4.7$ \\
\hline GRb2 & $361.4 \pm 74.3$ & $12.5 \pm 2.1$ & $8.0 \pm 0.0$ & $19.4 \pm 1.6$ & $24.6 \pm 6.7$ \\
\hline GRc & $508.6 \pm 109$ & $17.2 \pm 3.1$ & $8.0 \pm 0.0$ & $19.9 \pm 1.7$ & $22.8 \pm 6.7$ \\
\hline GRd & $278.8 \pm 117$ & $8.6 \pm 1.8^{*}$ & $13.3 \pm 9.2$ & $21.3 \pm 3.0$ & $24.2 \pm 3.1$ \\
\hline CK & $69.94 \pm 37.8$ & $3.6 \pm 1.4$ & $8.0 \pm 0.0$ & $13.9 \pm 5.3$ & $13.2 \pm 3.2$ \\
\hline PPD & $608.7 \pm 133.8$ & $29.3 \pm 7.0$ & $8.0 \pm 0.0$ & $12.6 \pm 4.7$ & $7.9 \pm 1.8$ \\
\hline \multirow[t]{2}{*}{ PPT } & $547.9 \pm 77.6$ & $20.3 \pm 8.9$ & $2.0 \pm 0.0$ & $20.2 \pm 2.2$ & $20.4 \pm 2.3$ \\
\hline & \multicolumn{5}{|c|}{ Amoxicillin } \\
\hline Ginsenosides & $\begin{array}{c}\text { AUC } \\
(\mathrm{ng} / \mathrm{mL} \cdot \mathrm{h})\end{array}$ & $\underset{(\mathrm{ng} / \mathrm{mL})}{\mathrm{C}_{\max }}$ & $\mathrm{T}_{\max }(\mathrm{h})$ & MRT (h) & Half-life (h) \\
\hline GRb1 & $926.0 \pm 439$ & $28.2 \pm 12.9$ & $8.0 \pm 0.0$ & $19.3 \pm 1.4$ & $21.7 \pm 3.6$ \\
\hline GRb2 & $391.5 \pm 192$ & $10.3 \pm 4.6$ & $13.3 \pm 9.2$ & $21.4 \pm 1.6$ & $25.1 \pm 2.7$ \\
\hline GRc & $571.7 \pm 276$ & $14.8 \pm 6.6$ & $13.3 \pm 9.2$ & $21.9 \pm 1.5$ & $25.1 \pm 9.9$ \\
\hline GRd & $132.4 \pm 77$ & $3.2 \pm 1.6$ & $24.7 \pm 23.0$ & $24.0 \pm 2.1$ & $29.1 \pm 8.6$ \\
\hline CK & $\mathrm{NC}$ & $\mathrm{NC}$ & $\mathrm{NC}$ & $\mathrm{NC}$ & $\mathrm{NC}$ \\
\hline PPD & $\mathrm{NC}$ & $\mathrm{NC}$ & $\mathrm{NC}$ & $\mathrm{NC}$ & $\mathrm{NC}$ \\
\hline PPT & $\mathrm{NC}$ & $\mathrm{NC}$ & $\mathrm{NC}$ & $\mathrm{NC}$ & $\mathrm{NC}$ \\
\hline
\end{tabular}

AUC: area under the plasma concentration-time curve from 0 to $48 \mathrm{~h} ; \mathrm{C}_{\max }$ : maximum plasma concentration; $\mathrm{T}_{\max }$ : time to reach $\mathrm{C}_{\max }$; MRT: mean residence time. NC: Not calculated. Data expressed as mean \pm standard deviation $(n=3) .{ }^{*} p<0.05$ compared with Amoxicillin group. 


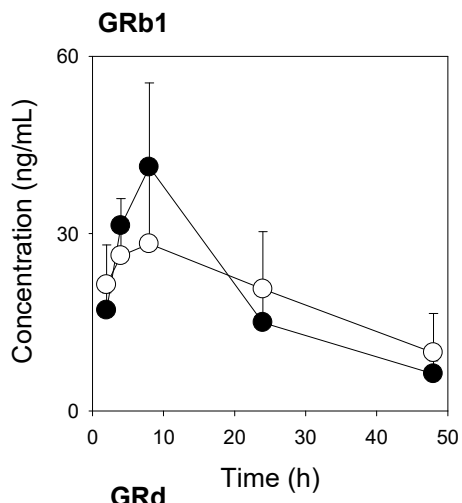

GRb2

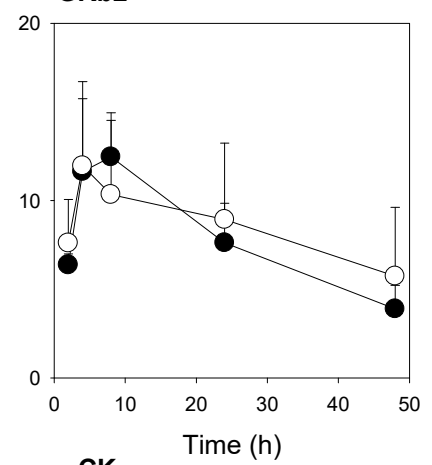

CK
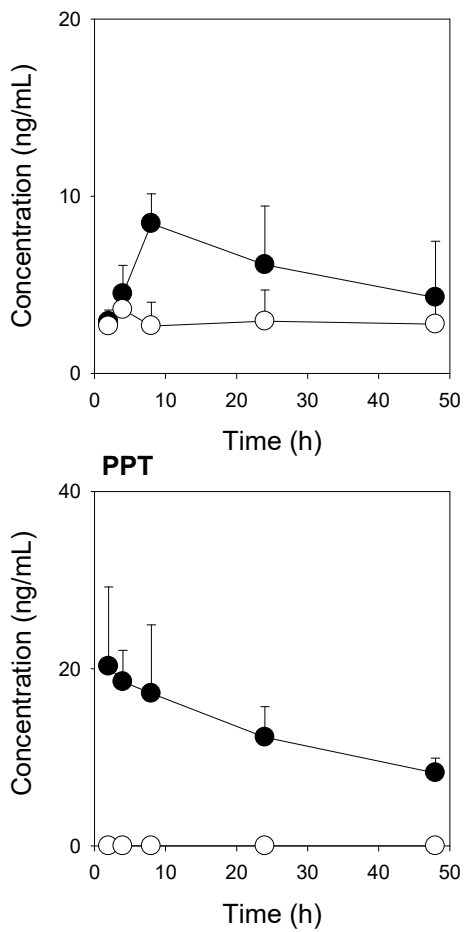

Control Amoxicillin
GRc

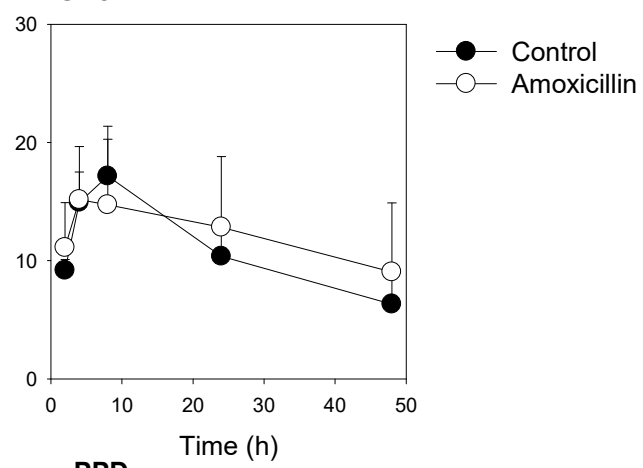

PPD

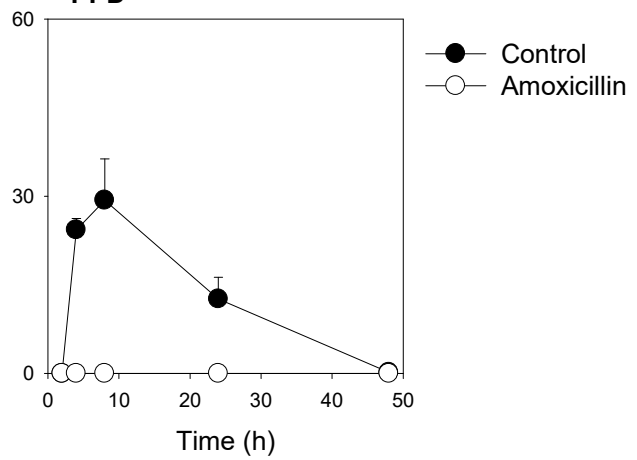

Figure 5. Plasma concentration-time profile of ginsenoside Rb1 (GRb1), GRc, GRd, CK, PPD, and PPT in mice following single oral administration of RGE $(2 \mathrm{~g} / \mathrm{kg})$ with or without amoxicillin treatment. Data point represents the mean \pm standard deviation $(n=3)$.

3.4. Plasma Concentrations of Ginsenosides Following Single Oral Administration of RGE after Repeated Oral Administration of Amoxicillin with or without Repeated LAB Treatment

To investigate how much the gut microbiota-mediated ginsenoside metabolic activity is repaired after LAB administration, we administered amoxicillin for 3 days followed by with or without LAB supplementation for 1 week and compared the ginsenoside pharmacokinetics between two groups (Figure 6A). The recovery of ginsenosides from urine and feces for $48 \mathrm{~h}$ has also been monitored. As shown in Figure 6B, urinary excretion of $\mathrm{Rd}$ was increased in the Amoxcillin + LAB group compared with that in the amoxicillin group, which reflects the increased plasma concentrations of $\mathrm{Rd}$. The urinary excretion of other ginsenosides was much lower than the fecal recovery and was not significantly affected by the LAB. In the feces (Figure 6C), the recovery of GRb1, GRb2, GRc, GRd, GRg3, GRe, GRf, and GRg1 was significantly decreased by LAB treatment. Considering these ginsenosides were glycosylated ginsenosides, the repeated administration of LAB decreased these ginsenosides by processing glycosylation. As results, their deglycosylated metabolite ginsenosides, such as CK, PPD, and PPT were significantly increased. The intermediated GRh2, GF2, GRh1, and GF1 remained similar in both groups. Moreover, we found that final metabolites, such as CK, PPD, and PPT, which were decreased in fecal excretion after 
amoxicillin administration due to inhibited metabolism, were much more or similarly repaired in both fecal excretion and plasma concentration after additional LAB treatment as a result of resumed metabolism compared with the amoxicillin group.

(A)

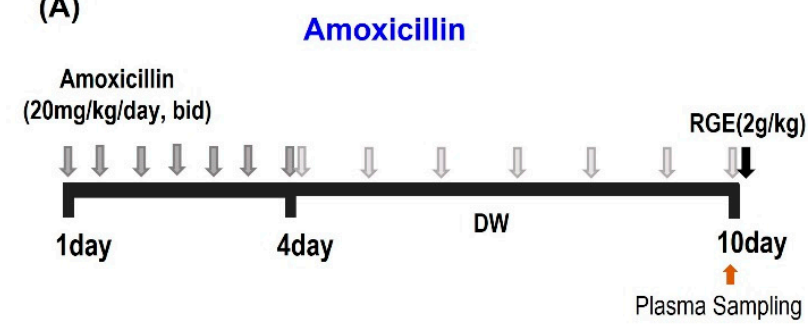

Amoxicillin + LAB

Amoxicillin $(20 \mathrm{mg} / \mathrm{kg} /$ day, bid $)$

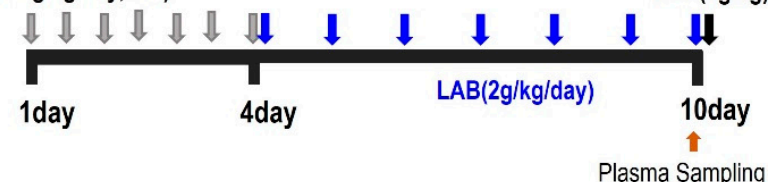

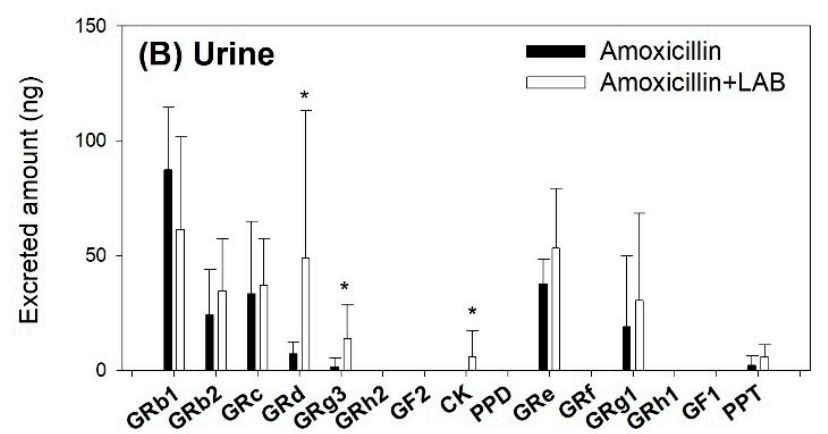

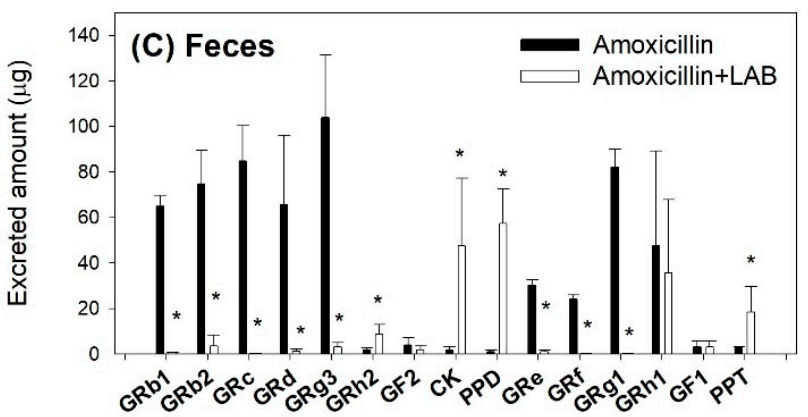

Figure 6. (A) Dosing schedule for repeated oral administrations of LAB followed by the amoxicillin (20 mg/ $\mathrm{kg} / \mathrm{day})$ pretreatment and the subsequent single oral administration of RGE $(2 \mathrm{~g} / \mathrm{kg})$. DW: distilled water. Recovery of ginsenosides from (B) urine and (C) feces for $48 \mathrm{~h}$ in mice following single oral administration of RGE ( $2 \mathrm{~g} / \mathrm{kg}$ ) after repeated oral administration of amoxicillin with or without repeated LAB treatment. Data expressed as mean \pm standard deviation $(n=3) .{ }^{*} p<0.05$ compared with Amoxicillin group.

Among the PPD-type ginsenosides, GRb1, GRb2, GRc, GRd, CK, PPD, and GRg3 were detected in mouse plasma samples following repeated LAB administration in addito to amoxicillin treatment. Especially, GRg3 was not detected in control mice and amoxicillin group. The results suggested that LAB treatment may increase the absorption or production of GRg3. However, PPT was only detected among the PPT-type ginsenosides (Figure 7). When compared the pharmacokinetic parameters, all parameters of GRb1, GRb2, and GRc from amoxicillin and LAB treatment were not different compared with amoxicillin group. The AUC and $C_{\max }$ value of Rd was significantly increased by the LAB treatment without reaching statistical significance in $\mathrm{T}_{\max }$, MRT, and half-life of GRd by LAB treatment (Table 6). CK, PPD, and PPT, deglycosylated metabolite ginsenosides that were not detected in amoxicillin treament (Figure 6), were all detected by the LAB supplementation, suggesting the role of $\mathrm{LAB}$ in the deglycosylated metabolism of ginsenoside. 

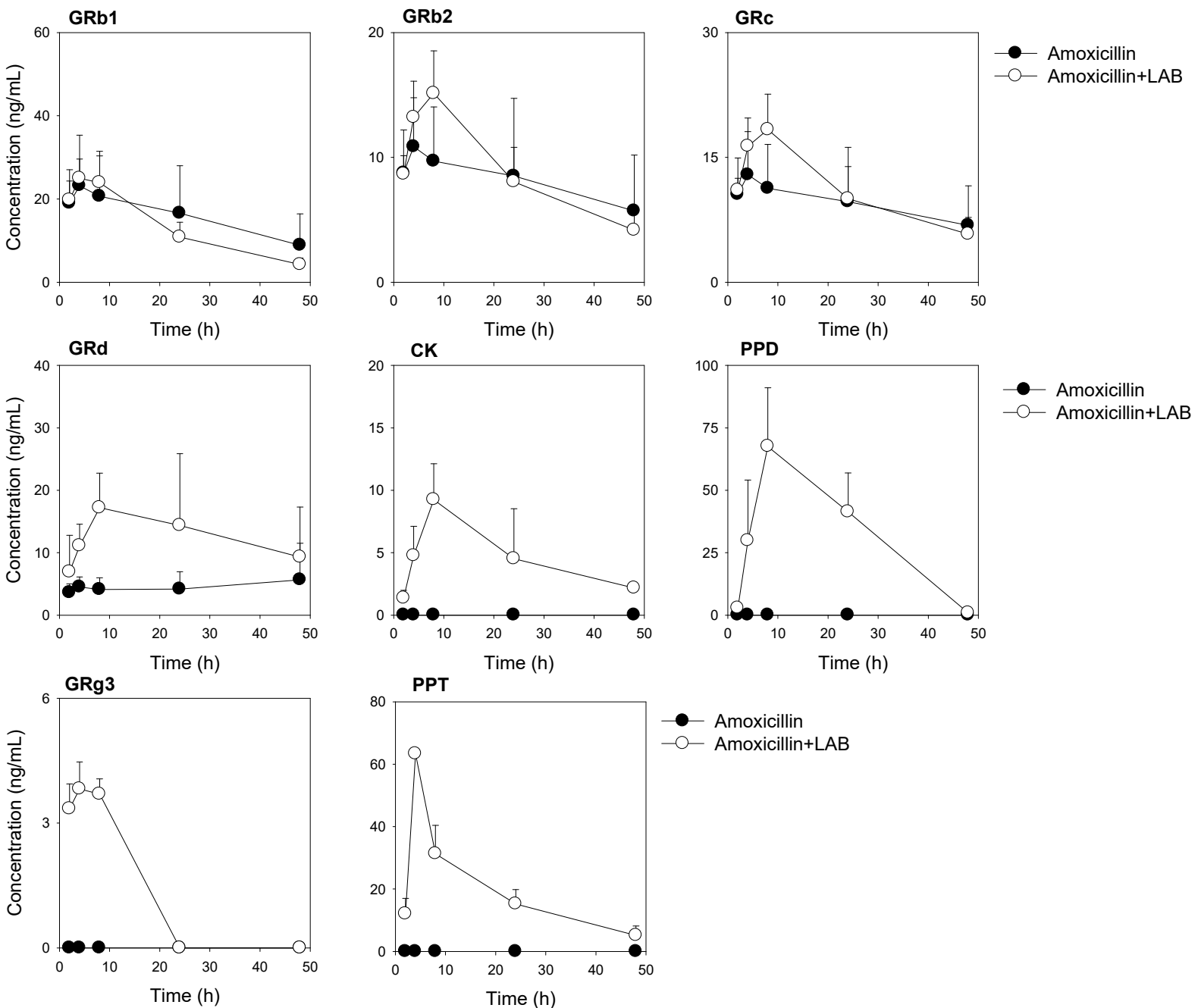

Figure 7. Plasma concentration-time profile of ginsenoside Rb1 (GRb1), GRb2, GRc, GRd, CK, PPD, GRg3, GF2, and PPT in mice following single oral administration of RGE $(2 \mathrm{~g} / \mathrm{kg})$ after repeated oral administration of amoxicillin with or without repeated LAB treatment. Data point represents the mean \pm standard deviation $(n=3)$.

\subsection{LAB-Mediated Metabolism of Ginsenoside}

To explain the LAB-mediated metabolism of ginsenoside and the resultant pharmacokinetic features, we incubated individual ginsenoside with $L A B$ and calculated the formation rate of ginsenoside (Figure 8). Incubation of tri- or tetraglycosylated-glycosylated PPD-type ginsenosides, GRb1, GRb2, GRc, and GRd with LAB produced GRg3 with the highest formation rate. Further metabolism from GRg3 to GRh2 and PPD was negligible after the incubation for 1 week. However, GRh2 and PPD were produced from Rg3 when incubating GRg3 with LAB. The results suggested the slow metabolism or losing deglycosylation activity in a week. The formation rate of CK from the incubation of GF2 and the formation of PPD from GRh2 were the highest among the ginsenoside formation rate and they were much higher than the formation rate of GF2 or CK from GRd or the formation rate of GRh2 or PPD from GRg3 (Figure 8A). The results suggested that the deglycosylation mediated by $\mathrm{LAB}$ was preferable at the $\mathrm{C} 3$ site of the ginsenoside structure [31] and this process might be mainly mediated by Lactobacillus rhamnosus and L. plantarum considering the involvement of these species and the composition of LAB formulation (content of L. rhamnosus and L. plantarum 59\%) [32,63,64]. Bifidobacterium longum (content 6\%) and Enterococcus sp. (content $6 \%$ ) also have been reported to be involved in the deglycosylaiton of PPD-type ginsenosides $[64,65]$. 
Table 6. Pharmacokinetic parameters of ginsenosides in mouse after single dosing RGE after repeated oral administration of amoxicillin with or without repeated LAB treatment.

\begin{tabular}{|c|c|c|c|c|c|}
\hline \multirow[b]{2}{*}{ Ginsenosides } & \multicolumn{5}{|c|}{ Amoxicillin } \\
\hline & $\begin{array}{c}\text { AUC } \\
(\mathrm{ng} / \mathrm{mL} \cdot \mathrm{h})\end{array}$ & $\underset{(\mathrm{ng} / \mathrm{mL})}{\mathrm{C}_{\max }}$ & $\mathrm{T}_{\max }(\mathrm{h})$ & MRT (h) & Half-Life (h) \\
\hline GRb1 & $752.3 \pm 477.6$ & $23.7 \pm 11.6$ & $3.3 \pm 1.2$ & $18.6 \pm 1.6$ & $20.1 \pm 2.2$ \\
\hline $\mathrm{GRb} 2$ & $385.9 \pm 243.6$ & $10.9 \pm 5.2$ & $4.0 \pm 0.0$ & $20.2 \pm 1.7$ & $19.2 \pm 2.3$ \\
\hline GRc & $448.2 \pm 268.1$ & $13.2 \pm 6.6$ & $4.7 \pm 3.1$ & $20.6 \pm 1.2$ & $20.2 \pm 1.8$ \\
\hline GRd & $213.1 \pm 151.3$ & $6.5 \pm 5.1$ & $5.3 \pm 2.3$ & $24.1 \pm 3.9$ & $29.2 \pm 2.7$ \\
\hline CK & NC & $\mathrm{NC}$ & $\mathrm{NC}$ & $\mathrm{NC}$ & $\mathrm{NC}$ \\
\hline PPD & NC & $\mathrm{NC}$ & $\mathrm{NC}$ & $\mathrm{NC}$ & NC \\
\hline GRg3 & $\mathrm{NC}$ & $\mathrm{NC}$ & $\mathrm{NC}$ & $\mathrm{NC}$ & $\mathrm{NC}$ \\
\hline \multirow[t]{2}{*}{ PPT } & NC & $\mathrm{NC}$ & $\mathrm{NC}$ & $\mathrm{NC}$ & NC \\
\hline & \multicolumn{5}{|c|}{ Amoxicillin + LAB } \\
\hline Ginsenosides & $\begin{array}{c}\text { AUC } \\
(\mathrm{ng} / \mathrm{mL} \cdot \mathrm{h})\end{array}$ & $\begin{array}{c}\mathrm{C}_{\max } \\
(\mathrm{ng} / \mathrm{mL})\end{array}$ & $\mathrm{T}_{\max }(\mathrm{h})$ & MRT (h) & Half-life (h) \\
\hline GRb1 & $622.1 \pm 163.6$ & $26.2 \pm 4.6$ & $4.7 \pm 3.1$ & $16.9 \pm 1.0$ & $16.2 \pm 0.9$ \\
\hline GRb2 & $419.2 \pm 108.6$ & $15.1 \pm 3.4$ & $8.0 \pm 0.0$ & $18.1 \pm 0.9$ & $21.6 \pm 1.7$ \\
\hline GRc & $524.4 \pm 146.6$ & $18.3 \pm 4.3$ & $8.0 \pm 0.0$ & $19.0 \pm 1.3$ & $24.1 \pm 2.4$ \\
\hline GRd & $618.1 \pm 385.6^{*}$ & $18.4 \pm 6.9^{*}$ & $16.0 \pm 9.2$ & $20.6 \pm 3.7$ & $25.5 \pm 3.8$ \\
\hline CK & $249.8 \pm 103.0$ & $9.3 \pm 2.9$ & $8.0 \pm 0.0$ & $13.7 \pm 6.2$ & $12.0 \pm 5.0$ \\
\hline PPD & $1607.3 \pm 463.7$ & $73.0 \pm 14.6$ & $6.7 \pm 2.3$ & $16.0 \pm 1.2$ & $18.4 \pm 2.2$ \\
\hline GRg3 & $25.3 \pm 10.6$ & $4.8 \pm 1.9$ & $2.5 \pm 1.0$ & $3.5 \pm 0.9$ & $5.3 \pm 1.1$ \\
\hline PPT & $894.4 \pm 161.3$ & $63.4 \pm 0.6$ & $4.0 \pm 0.0$ & $13.7 \pm 2.9$ & $14.4 \pm 3.0$ \\
\hline
\end{tabular}

AUC: area under the plasma concentration-time curve from 0 to $48 \mathrm{~h} ; \mathrm{C}_{\max }$ : maximum plasma concentration $\mathrm{T}_{\max }$ : time to reach $\mathrm{C}_{\max } ; \mathrm{MRT}$ : mean residence time. NC: Not calculated. Data expressed as mean \pm standard deviation $(n=3) .{ }^{*} p<0.05$ compared with control group.

(A) PPD-type ginsenoside

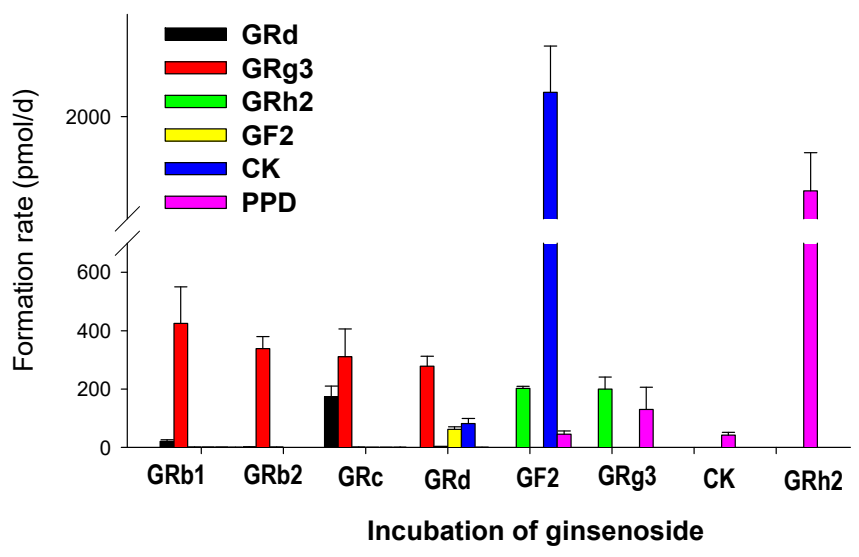

(B) PPT-type ginsenoside

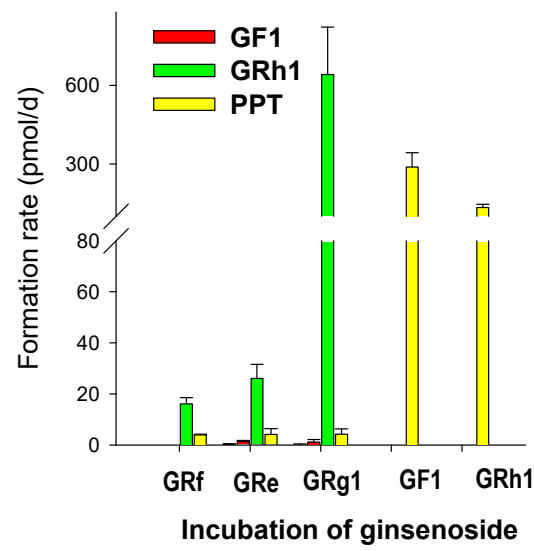

Figure 8. Formation rate of metabolite ginsenoside following the incubation of single ginsenoside with LAB. (A) PPD-type ginsenosides: GRb1, GRb2, GRc, GRd, GF2, GRg3, CK, and GRh2 and (B) PPT-type ginsenosides: GRf, GRe, GRg1, GF1, and GRh1 were incubated in the presence of LAB for 7 days. Data expressed as mean \pm standard deviation $(n=3)$.

Similarly, the incubation of diglycosylated PPT-type ginsenosides, GRe, GRf, and GRg1 with LAB produced GRh1. Among these metabolisms, the formation rate of GRh1 from GRg1 showed the highest formation rate. Further metabolism to GF2 or PPD was also negligible. However, the greater formation rate of PPT from GF1 or GRh1 and the greater formation rate of GRh1 from GRg1 than the formation rate of GF1 suggested the preferable formation of PPT from GRh1 (i.e., deglycosylation at C20 site of ginsenoside structure [31]), mediated by LAB (Figure 8B). Bacteroides sp. and Bifidobacterium sp. are mainly involved in the deglycosylaiton of PPT-type ginsenosides [66]. Additonally, 
the results also suggested the sequential and stepwise deglycosylation metabolism of ginsenoside by LAB either in PPD-type or PPT-type.

\subsection{Permeability, Protein Binding, and Stability of Ginsenosides}

In summary, plasma exposure of GRd, GRg3, GF2, CK, PPD, and PPT was increased by the repeated administrations of LAB following amoxicillin pretreatment. However, GRh1 and GRh2 were not found in the mouse plasma despite of high formation rate from Rg1, and GF2/GRg3, as well as considerable amount of GRh1 was detected in the feces. To explain the limited existence of GRh1 and GRh2 in mouse plasma, we measured the apparent A to B permeability $\left(\mathrm{P}_{\mathrm{app}, \mathrm{AB}}\right)$, plasma protein binding, plasma stability, and microsomal stability of 15 ginsenosides (Figure 9) since these properties affect the pharmacokinetics of ginsenosides in addition to their gut metabolism. For the feasibility of our system, positive control studies using marker compounds for Caco-2 permeability, plasma protein binding, and microsomal stability were performed. $\mathrm{P}_{\mathrm{app}, \mathrm{AB}}$ values of caffeine and propranolol (marker for high permeability) were $29.65 \pm 3.77 \times 10^{-6} \mathrm{~cm} / \mathrm{s}$ and $21.60 \pm 2.35 \times 10^{-6} \mathrm{~cm} / \mathrm{s}$, respectively, similar to the reference values $\left(18.8-33.1 \times 10^{-6} \mathrm{~cm} / \mathrm{s}\right)$. $\mathrm{P}_{\mathrm{app}, \mathrm{AB}}$ values of ofloxacin and atenolol, moderate and low permeable marker, respectively, were $5.10 \pm 0.71 \times 10^{-6} \mathrm{~cm} / \mathrm{s}$ and $0.46 \pm 0.14 \times 10^{-6} \mathrm{~cm} / \mathrm{s}$, respectively, similar to the reference values $\left(5.3-8.8 \times 10^{-6}\right.$ $\mathrm{cm} / \mathrm{s}$ and $0.38-0.45 \times 10^{-6} \mathrm{~cm} / \mathrm{s}$, respectively) in previous papers [62,67-69]. Plasma protein binding of atenolol and propranolol was $5.6 \pm 0.2 \%$ and $89.7 \pm 0.2 \%$, respectively, similar to the reference values (lee than $5 \%$ and $87-96 \%$, respectively $[70,71]$. The percent of remaining metformin and propranolol after $1 \mathrm{~h}$ incubation in the mouse liver microsomes was $69.35 \pm 3.00 \%$ and $17.87 \pm 2.33 \%$, respectively, which was similar to the previous results [53,55].

As shown in Figure 9A, PPT seemed to be moderately permeable in Caco-2 cells with $\mathrm{P}_{\mathrm{app}, \mathrm{AB}}$ value of $3.72 \pm 0.56 \times 10^{-6} \mathrm{~cm} / \mathrm{s}$, compared with the $\mathrm{P}_{\mathrm{app}, \mathrm{AB}}$ value of ofloxacin. The permeability of the other 14 ginsenosides was below $0.3 \times 10^{-6} \mathrm{~cm} / \mathrm{s}$, suggesting the low permeability of 14 ginsenosides except for PPT. Nine PPD-type ginsenosides seem to be more permeable as they are deglycosylated but the $\mathrm{P}_{\mathrm{app}, \mathrm{AB}}$ value of PPT-type were not correlated with the number of sugar (Figure 9A right panel). Even the lowest permeable tetraglycosylated ginsenosides GRb1, GRb2, and GRc were found in the plasma (Figures 5 and 7). Average TEER values before and after the transport study were $394 \pm 64 \Omega \cdot \mathrm{cm}^{2}$ and $376 \pm 44 \Omega \cdot \mathrm{cm}^{2}$, respectively and the alterations were less than $10 \%$ in all cases.

The plasma protein binding of nine PPD-type ginsenosides was over $99 \%$ and unaltered depending on the sugar number. However, the plasma protein binding of 6 PPT-type ginsenosides differed depending on their glycosylation states (Figure 9B). More specifically, the amount of plasma protein binding of triglycosylated PPT-type GRe, GRf, and GRg1 was approximately $65-80 \%$. The protein-bound fraction increased with increasing deglycosylation, as the protein binding of GF1 and PPT increased to over 99\% (Figure 9B right panel).

When monitoring the plasma stability of 15 ginsenosides, all ginsenosides were stable from the incubation of these ginsenosides in the mouse plasma for $2 \mathrm{~h}$ (Figure 9C). Highly glycosylated ginsenosides with over the sugar number of two were stable from the incubation of these ginsenosides in the mouse liver microsomes for $1 \mathrm{~h}$ (Figure 9D). The monoglycosylated or deglycosylated ginsenosides, GRh2, PPD, GRh1, and PPT were unstable from the mouse liver microsomal incubation for $1 \mathrm{~h}$ (Figure 9D). 

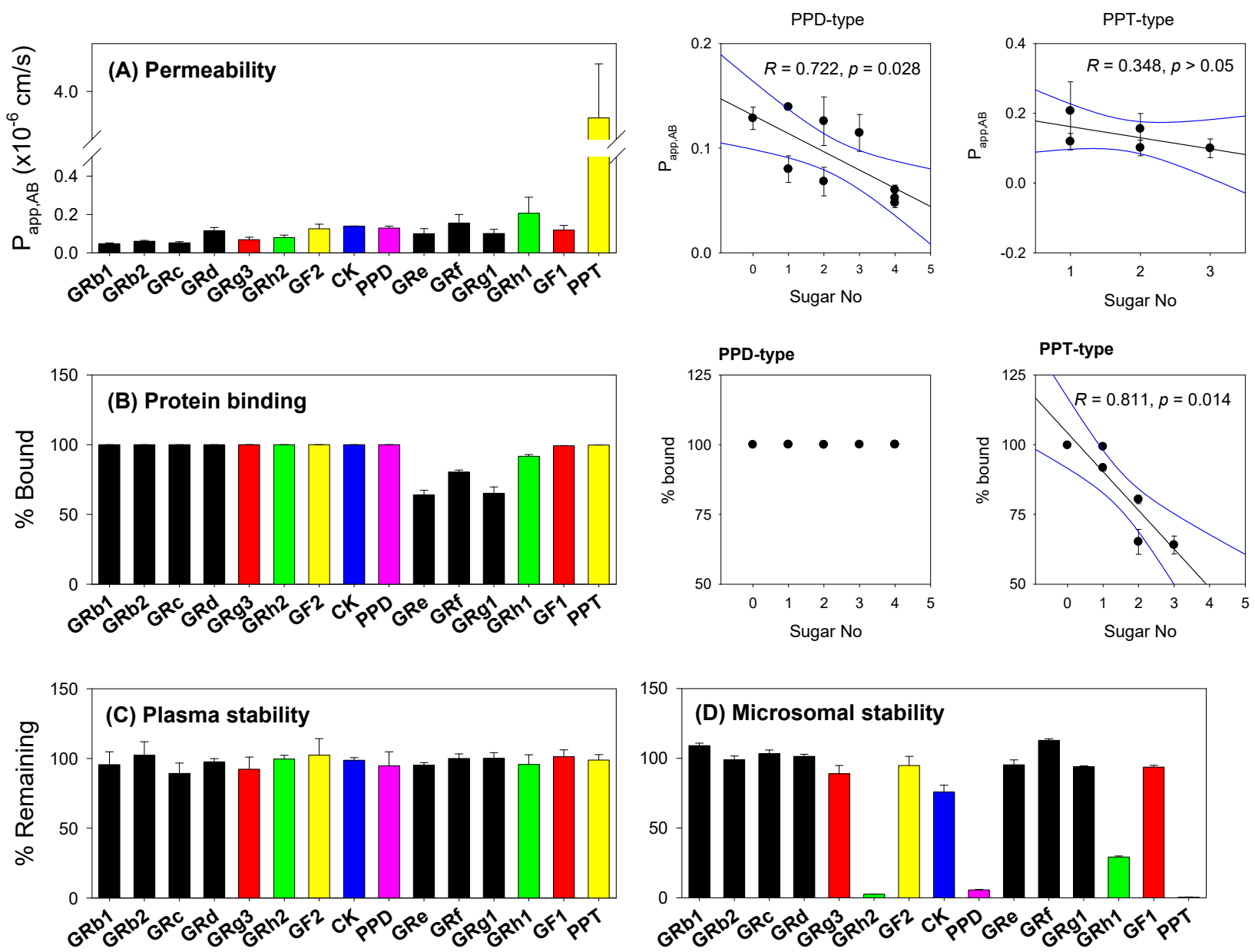

Figure 9. (A) The apical to basal permeability $\left(\mathrm{P}_{\mathrm{app}, \mathrm{AB}}\right)$ of 15 ginsenosides was measured in Caco-2 cell monolayers. Correlation analysis between $\mathrm{P}_{\mathrm{app}, \mathrm{AB}}$ of 9 PPD-type ginsenosides and 5 PPT-type ginsenosides except for PPT (total) and the sugar number of these ginsenosides was shown in the right panel. (B) Plasma protein binding of 15 ginsenosides were measured in mouse plasma using a rapid equilibrium kit. Correlation analysis between plasma protein binding ( $\%$ bound) of 9 PPD-type and 6 PPT-type ginsenosides and the sugar number of these ginsenosides was shown in the right panel. (C) Plasma stability of 15 ginsenosides was measured in mouse plasma. (D) The metabolic stability of 15 ginsenosides was measured using mouse liver microsomes. Data expressed as mean \pm standard deviation $(n=3)$.

\section{Discussion}

Even though the involvement of LAB in the ginsenoside metabolism has been reported, the effect of LAB on plasma concentrations of ginsenosides has not been investigated in vivo. To minimize the microbiota-mediated metabolism in the gut, we pretreated amoxicillin, which is susceptible to probiotic Lactobacillis and Bifidobacterium species [50-52], for 3 days. The amoxicillin pretreatment maintained the concentrations of amoxicillin in the range of $0.9-1.8 \mu \mathrm{g} / \mathrm{mL}$ for $72 \mathrm{~h}$, which could change the ginsenoside metabolism in the gut. The recovery of GF2, CK, PPD, and PPT from the feces after single oral administration of RGE $(2 \mathrm{~g} / \mathrm{kg})$ was significantly decreased by the amoxicillin treatment, suggesting the blockade of gut microbiota-mediated deglycosylation of ginsenoside. As a result, the amount of ginsenosides with a sugar number of one or zero (i.e., CK, GRh2, PPD, GF1, and PPT) was decreased, but ginsenosides with a sugar number of more than three were increased (Figure 4D). Plasma concentrations of ginsenosides reflected these alterations. Consistent with the fecal recovery, the plasma exposure of CK, PPD, and PPT was not detectable after the amoxicillin pretreatment (Figure 5). These results suggested that alterations in the gut microbiota environment could change the ginsenoside metabolism and plasma concentrations of ginsenosides. In addition, LAB supplementation showed 
much higher AUC values of PPD and PPT $(1607.3 \pm 463.7 \mathrm{ng} / \mathrm{mL} \cdot \mathrm{h}$ for PPD and $894.4 \pm$ $161.3 \mathrm{ng} / \mathrm{mL} \cdot \mathrm{h}$ for PPT) compared with control groups $(608.7 \pm 133.8 \mathrm{ng} / \mathrm{mL} \cdot \mathrm{h}$ for PPD and $547.9 \pm 77.6 \mathrm{ng} / \mathrm{mL} \cdot \mathrm{h}$ for PPT) $(p<0.05)$. The high and stable plasma concentrations of PPD and PPT in the LAB supplemented group can be explained by the more efficient metabolic conversion from CK or GRh2 to PPD and from GRh1 to PPT (Figure 1) compared with intrinsic activity mediated by gut microbiota. Considering the therapeutic benefits of deglycosylated ginsenosides such as GRg3, CK, PPD, and PPT, the pharmacokinetic alteration of ginsenosides depends on the glycosylation states by the LAB supplementation need further investigation in relation to their pharmacological activities.

The appearance of GRg3 in mouse plasma following LAB supplementation (Figure 7) could be attributed to the preferable formation of GRg3 from GRb1, GRb2, GRc, and GRd that are the most abundant ginsenosides in RGE in addition to the great increase in CK, PPD, and PPT from the incubation of RGE with LAB (Figures 3 and 8). Consistent with this, GRg3 was detected in mouse plasma samples following repeated administrations of RGE ( $2 \mathrm{~g} / \mathrm{kg} /$ day) for 14 days [31]. Kim et al. [72] reported that the plasma AUCs of GRd, GRg3, GF2, and CK were correlated with the intake amount of these ginsenosides in humans. Additionally, plasma concentrations of GRg3 after the oral intake of black ginseng, which contains a higher amount of GRg3 than RGE, were significantly higher than that after oral intake of RGE in human [73]. Contrary to the case of GRg3, GRh1 and GRh2 was not detected in the plasma from mice supplemented with LAB. The metabolic instability of GRh2 and GRh1 in mouse liver microsomes (Figure 9D) could explain the limited appearance of these ginsenosides despite of the high formation rate of GRh2 and GRh1 from the LAB incubation (Figure 8) as well as the comparable permeability, plasma protein binding, and plasma stability compared with GRg3 (Figure 9). We also should note that most PPD-type ginsenosides except for GRh2 appeared in mouse plasma, whereas only PPT was detected in mouse plasma following the oral intake of RGE followed by LAB supplementation. It suggested difference in absorption, distribution, excretion mechanism between PPD-type and PPT-type ginsenosides that need further investigation. The high plasma protein binding (Figure 9B), low hepatic distribution (i.e., Ratio of liver AUC to plasma AUC < 0.2 [60]), metabolic and plasma stability (Figure 9C,D) of GRb1, GRb2, GRc, and GRd could coordinately contribute to the long plasma circulation time of these ginsenosides. Jiang et al. [74] reported the substrate specificity for organic anion transporting polypeptide (OATP)1B3 of highly glycosylated PPT-type GRe and GRg1. In addition to the low plasma protein binding (Figure 9B), the substrate specificity to OATP1B3 could account for its fast elimination of GRe and GRg1 (Figure 6B). In our urine samples, GRe and GRg1 were detected after oral administration of RGE (Figures 4C and 6B), suggesting the absorption into plasma and fast elimination process of these ginsenosides. Contrary to these highly glycosylated ginsenosides, metabolic instability of GRg3, GRh1, GRh2, CK, PPD, and PPT (Figure 9D) could facilitate the elimination of GRg3, CK, PPD, and PPT from the plasma. Consistent with this, PPD and PPT were reported to be subjected to hepatic cytochrome P450 (P450)-catalyzed metabolism in liver microsomes [75].

\section{Conclusions}

In this study, we first reported the effect of $\mathrm{LAB}$ supplementation on the formation rate of deglycosylated gensenosides, such as CK, PPD, and PPT and on the pharmacokinetics of these deglycosylated ginsenosides in mice. In vitro fermentation of RGE with LAB indicated the highest formation rate of CK, PPD, and PPT that are not in RGE but pharmacologically active metabolites of ginsenosides. This could be explained by the preferable and sequential deglycosylation process of PPD- or PPT-type ginsenosides (i.e., GF2 $\rightarrow$ CK, GRg3 $\rightarrow$ GRh2 $\rightarrow$ PPD, and GRh1 $\rightarrow$ PPT). In conclusion, LAB supplementation through the repeated administration of $\mathrm{LAB}$ for 1 week after the amoxicillin treatment restored the ginsenoside metabolism and recovered the pharmacokinetics of ginsenosides in mice. 
Author Contributions: Conceptualization, J.-H.J. and I.-S.S.; methodology, J.-H.J. and M.-K.C.; investigation, J.-H.J., J.L., J.-H.P., C.-H.L., M.-K.C. and I.-S.S.; data analysis and interpretation, J.-H.J., J.L., J.-H.P. and C.-H.L.; writing-original draft preparation, J.-H.J.; writing-review and editing, M.-K.C. and I.-S.S.; supervision, I.-S.S.; grant acquisition, I.-S.S. All authors have read and agreed to the published version of the manuscript.

Funding: This work was supported, in part, by the National Research Foundation of Korea (NRF) grant funded by the Korea government (MSIT) (No. NRF-2020R1I1A3074384 and NRF-2020R1A5A 2017323).

Institutional Review Board Statement: All animal procedures were approved by the Animal Care and Use Committee of Kyungpook National University (Protocol code: 2020-0060, date of approval: 14 April 2020) and carried out in accordance with the National Institutes of Health guidelines for the care and use of laboratory animals.

Informed Consent Statement: Not applicable.

Data Availability Statement: The data presented in this study are available upon request.

Conflicts of Interest: The authors declare no conflict of interest.

\section{References}

1. Won, H.-J.; Kim, H.I.; Park, T.; Kim, H.; Jo, K.; Jeon, H.; Ha, S.J.; Hyun, J.M.; Jeong, A.; Kim, J.S.; et al. Non-clinical pharmacokinetic behavior of ginsenosides. J. Ginseng Res. 2018, 43, 354-360. [CrossRef]

2. Leung, K.W.; Wong, A.S. Pharmacology of ginsenosides: A literature review. Chin. Med. 2010, 5, 20-27. [CrossRef]

3. Kim, J.H.; Yi, Y.-S.; Kim, M.-Y.; Cho, J.Y. Role of ginsenosides, the main active components of Panax ginseng, in inflammatory responses and diseases. J. Ginseng Res. 2016, 41, 435-443. [CrossRef]

4. Gui, Q.F.; Xu, Z.R.; Xu, K.Y.; Yang, Y.M. The efficacy of ginseng-related therapies in type 2 diabetes mellitus: An updated systematic review and meta-analysis. Medicine 2016, 95, e2584. [CrossRef]

5. Zhan, S.; Guo, W.; Shao, Q.; Fan, X.; Li, Z.; Cheng, Y. A pharmacokinetic and pharmacodynamic study of drug-drug inter-action between ginsenoside $\mathrm{Rg} 1$, ginsenoside $\mathrm{Rb} 1$ and schizandrin after intravenous administration to rats. J. Ethnopharmacol. 2014, 152, 333-339. [CrossRef]

6. Zhan, S.-Y.; Shao, Q.; Li, Z.; Wang, Y.; Fan, X.-H. Study on PK-PD characteristics of ginsenoside Rg1 and Rb1, in rats with myocardial ischemia following intravenous administration of shengmai injection. China J. Chin. Mater. Med. 2014, 39, 1300-1305.

7. Jeon, J.-H.; Kang, B.; Lee, S.; Jin, S.; Choi, M.-K.; Song, I.-S. Pharmacokinetics and intestinal metabolism of compound K in rats and mice. Pharmaceutics 2020, 12, 129. [CrossRef] [PubMed]

8. Chen, L.; Zhou, L.; Huang, J.; Wang, Y.; Yang, G.; Tan, Z.; Wang, Y.; Zhou, G.; Liao, J.; Ouyang, D. Single- and multiple-dose trials to determine the pharmacokinetics, safety, tolerability, and sex effect of oral ginsenoside compound $\mathrm{K}$ in healthy Chinese volunteers. Front. Pharmacol. 2018, 8, 965. [CrossRef] [PubMed]

9. Chen, L.L.; Zhou, L.P.; Wang, Y.Q.; Yang, G.P.; Huang, J.; Tan, Z.R.; Wang, Y.; Zhou, G.; Liao, J.; Ouyang, D. Food and sex-related impacts on the pharmacoki-netics of a single-dose of ginsenoside compound $\mathrm{K}$ in healthy subjects. Front. Pharmacol. 2017, 8, 636. [CrossRef] [PubMed]

10. Choi, I.-D.; Ryu, J.-H.; Lee, D.-E.; Lee, M.H.; Shim, J.-J.; Ahn, Y.-T.; Sim, J.-H.; Huh, C.-S.; Shim, W.-S.; Yim, S.-V.; et al. Enhanced absorption study of ginsenoside compound K (20-O-beta-(D-glucopyranosyl)-20(S)-protopanaxadiol) after oral administration of fermented red ginseng extract (HYFRG) in healthy Korean volunteers and rats. Evid. Based. Complement. Alternat. Med. 2016, 2016, 3908142. [CrossRef] [PubMed]

11. Kim, H.K. Pharmacokinetics of ginsenoside Rb1 and its metabolite compound K after oral administration of Korean red ginseng extract. J. Ginseng Res. 2013, 37, 451-456. [CrossRef]

12. Jung, J.-W.; Kang, H.-R.; Ji, G.-E.; Park, M.-S.; Song, W.-J.; Kim, M.-H.; Kwon, J.-W.; Kim, T.-W.; Park, H.-W.; Cho, S.-H.; et al. Therapeutic effects of fermented red ginseng in allergic rhinitis: A randomized, double-blind, placebo-controlled study. Allergy Asthma Immunol. Res. 2011, 3, 103-110. [CrossRef] [PubMed]

13. Zhang, Z.; Du, G.-J.; Wang, C.-Z.; Wen, X.-D.; Calway, T.; Li, Z.; He, T.-C.; Du, W.; Bissonnette, M.; Musch, M.W.; et al. Compound $\mathrm{K}$, a ginsenoside metabolite, inhibits colon cancer growth via multiple pathways including p53-p21 Interactions. Int. J. Mol. Sci. 2013, 14, 2980-2995. [CrossRef] [PubMed]

14. Xu, T.; Jin, Z.; Yuan, Y.; Wei, H.; Xu, X.; He, S.; Chen, S.; Hou, W.; Guo, Q.; Hua, B. Ginsenoside Rg3 serves as an adjuvant chemotherapeutic agent and vegf inhibitor in the treatment of non-small cell lung cancer: A meta-analysis and systematic review. Evid.-Based Complement. Altern. Med. 2016, 2016, 7826753. [CrossRef] [PubMed]

15. Chen, S.; Wang, Z.; Huang, Y.; O’Barr, S.A.; Wong, R.A.; Yeung, S.; Chow, M.S.S. Ginseng and anticancer drug combination to improve cancer chemotherapy: A critical review. Evid.-Based Complement. Altern. Med. 2014, 2014, 168940. [CrossRef] [PubMed]

16. Yang, X.-D.; Yang, Y.-Y.; Ouyang, D.-S.; Yang, G.-P. A review of biotransformation and pharmacology of ginsenoside compound K. Fitoterapia 2015, 100, 208-220. [CrossRef] [PubMed] 
17. Huang, J.Y.; Sun, Y.; Fan, Q.X.; Zhang, Y.Q. Efficacy of Shenyi capsule combined with gemcitabine plus cisplatin in treatment of advanced esophageal cancer: A randomized controlled trial. Zhong Xi Yi Jie He Xue Bao 2009, 7, 1047-1051. [CrossRef] [PubMed]

18. Li, Y.; Wang, Y.; Niu, K.; Chen, X.; Xia, L.; Lu, D.; Kong, R.; Chen, Z.; Duan, Y.; Sun, J. Clinical benefit from EGFR-TKI plus ginsenoside Rg3 in patients with advanced non-small cell lung cancer harboring EGFR active mutation. Oncotarget 2016, 7, 70535-70545. [CrossRef] [PubMed]

19. Peng, Z.; Wu, W.W.; Yi, P. The efficacy of ginsenoside Rg3 combined with first-line chemotherapy in the treatment of advanced non-small cell lung cancer in China: A systematic review and meta-analysis of randomized clinical trials. Front. Pharmacol. 2021, 11, 630825. [CrossRef] [PubMed]

20. Choi, M.-K.; Song, I.-S. Interactions of ginseng with therapeutic drugs. Arch. Pharmacal Res. 2019, 42, 862-878. [CrossRef]

21. Zhao, Q.; Li, P.; Jiang, J.; Hu, P. Pharmacokinetics of single ascending doses and multiple doses of 20(S)-ginsenoside Rg3 in Chinese healthy volunteers. Eur. J. Drug Metab. Pharmacokinet. 2015, 41, 845-853. [CrossRef]

22. Yoon, S.J.; Kim, S.K.; Lee, N.Y.; Choi, Y.R.; Kim, H.S.; Gupta, H.; Youn, G.S.; Sung, H.; Shin, M.J.; Suk, K.T. Effect of Korean red ginseng on metabolic syndrome. J. Ginseng Res. 2020, 45, 380-389. [CrossRef] [PubMed]

23. Yuan, H.-D.; Kim, J.T.; Kim, S.; Chung, S.-H. Ginseng and diabetes: The evidences from in vitro, animal and human studies. J. Ginseng Res. 2012, 36, 27-39. [CrossRef] [PubMed]

24. Kim, H.G.; Kim, K.Y.; Cha, C.J. Screening for ginseng-fermenting microorganism capable of biotransforming ginsenosides. Korean J. Microbiol. 2007, 43, 142-146.

25. Jang, S.-H.; Park, J.; Kim, S.-H.; Choi, K.-M.; Ko, E.-S.; Cha, J.-D.; Lee, Y.-R.; Jang, H.; Jang, Y.-S. Red ginseng powder fermented with probiotics exerts antidiabetic effects in the streptozotocin-induced mouse diabetes model. Pharm. Biol. 2016, 55, 317-323. [CrossRef] [PubMed]

26. Park, S.-H.; Oh, M.-R.; Choi, E.-K.; Kim, M.-G.; Ha, K.-C.; Lee, S.-K.; Kim, Y.-G.; Park, B.-H.; Kim, D.-S.; Chae, S.-W. An 8-wk, randomized, double-blind, placebo-controlled clinical trial for the antidiabetic effects of hydrolyzed ginseng extract. J. Ginseng Res. 2014, 38, 239-243. [CrossRef]

27. Lee, H.-S.; Kim, M.-R.; Park, Y.; Park, H.J.; Chang, U.J.; Kim, S.Y.; Suh, H.J. Fermenting red ginseng enhances its safety and efficacy as a novel skin care anti-aging ingredient: In vitro and animal study. J. Med. Food 2012, 15, 1015-1023. [CrossRef]

28. Nan, B.; Liu, Y.-L.; You, Y.; Li, W.-C.; Fan, J.-J.; Wang, Y.-S.; Piao, C.-H.; Hu, D.-L.; Lu, G.-J. Protective effects of enhanced minor ginsenosides in Lactobacillus fermentum KP-3-fermented ginseng in mice fed a high fat diet. Food Funct. 2018, 9, 6020-6028. [CrossRef]

29. Trinh, H.-T.; Han, S.-J.; Kim, S.-W.; Lee, Y.C.; Kim, N.-H. Bifidus fermentation increases hypolipidemic and hypoglycemic effects of red ginseng. J. Microbiol. Biotechnol. 2007, 17, 1127-1133.

30. Jin, S.; Lee, C.; Lim, D.; Lee, J.; Park, S.-J.; Song, I.-S.; Choi, M.-K. Improved hygroscopicity and bioavailability of solid dispersion of red ginseng extract with silicon dioxide. Pharmaceutics 2021, 13, 1022. [CrossRef]

31. Jeon, J.-H.; Lee, J.; Choi, M.-K.; Song, I.-S. Pharmacokinetics of ginsenosides following repeated oral administration of red ginseng extract significantly differ between species of experimental animals. Arch. Pharmacal Res. 2020, 43, 1335-1346. [CrossRef]

32. Park, S.-E.; Na, C.-S.; Yoo, S.-A.; Seo, S.-H.; Son, H.-S. Biotransformation of major ginsenosides in ginsenoside model culture by lactic acid bacteria. J. Ginseng Res. 2015, 41, 36-42. [CrossRef] [PubMed]

33. Dong, W.W.; Zhao, J.; Zhong, F.L.; Zhu, W.J.; Jiang, J.; Wu, S.; Yang, D.C.; Li, D.; Quan, L.H. Biotransformation of panax ginseng extract by rat intestinal microflora: Identification and quantification of metabolites using liquid chromatography-tandem mass spectrometry. J. Ginseng Res. 2017, 41, 540-547. [CrossRef]

34. Jin, S.; Jeon, J.-H.; Lee, S.; Kang, W.Y.; Seong, S.J.; Yoon, Y.-R.; Cho, H.-J.; Song, I.-S. Detection of 13 ginsenosides (Rb1, Rb2, Rc, Rd, $\mathrm{Re}, \mathrm{Rf}, \mathrm{Rg} 1, \mathrm{Rg} 3$, Rh2, F1, compound K, 20(S)-protopanaxadiol, and 20(S)-protopanaxatriol) in human plasma and application of the analytical method to human pharmacokinetic studies following two week-repeated administration of red ginseng extract. Molecules 2019, 24, 2618. [CrossRef]

35. Doh, E.S.; Chang, J.P.; Lee, K.H.; Seong, N.S. Ginsenoside change and antioxidation activity of fermented ginseng. Korean J. Med. Crop Sci. 2010, 18, 255-265.

36. Kang, B.-H.; Lee, K.-J.; Hur, S.-S.; Lee, D.-S.; Lee, S.-H.; Shin, K.-S.; Lee, J.-M. Ginsenoside derivatives and quality characteristics of fermented ginseng using lactic acid bacteria. Korean J. Food Preserv. 2013, 20, 573-582. [CrossRef]

37. Liu, H.; Yang, J.; Du, F.; Gao, X.; Ma, X.; Huang, Y.; Xu, F.; Niu, W.; Wang, F.; Mao, Y.; et al. Absorption and disposition of ginsenosides after oral administration of Panax notoginseng extract to rats. Drug Metab. Dispos. 2009, 37, 2290-2298. [CrossRef] [PubMed]

38. Quan, L.H.; Kim, Y.J.; Li, G.H.; Choi, K.T.; Yang, D.C. Microbial transformation of ginsenoside rb1 to compound k by lacto-Bacillus paralimentarius. World J. Microbiol. Biotechnol. 2013, 29, 1001-1007. [CrossRef] [PubMed]

39. Chi, H.; Kim, D.-H.; Ji, G.-E. Transformation of ginsenosides Rb2 and Rc from Panax ginseng by food microorganisms. Biol. Pharm. Bull. 2005, 28, 2102-2105. [CrossRef] [PubMed]

40. Bae, E.-A.; Shin, J.-E.; Kim, D.-H. Metabolism of ginsenoside re by human intestinal microflora and its estrogenic effect. Biol. Pharm. Bull. 2005, 28, 1903-1908. [CrossRef]

41. Chi, H.L.; Lee, B.H.; You, H.J.; Park, M.S.; Ji, G.E. Differential transformation of ginsenosides from Panax ginseng by lactic acid bacteria. J. Microbiol. Biotech. 2006, 16, 1629-1633. 
42. Bae, E.-A.; Park, S.-Y.; Kim, D.-H. Constitutive beta-glucosidases hydrolyzing ginsenoside Rb1 and Rb2 from human intestinal bacteria. Biol. Pharm. Bull. 2000, 23, 1481-1485. [CrossRef]

43. Bae, E.A.; Choo, M.K.; Park, E.K.; Park, S.Y.; Shin, H.Y.; Kim, D.H. Metabolism of ginsenoside r(c) by human intestinal bacteria and its related antiallergic activity. Biol. Pharm. Bull. 2002, 25, 743-747. [CrossRef] [PubMed]

44. Kim, D. Metabolism of ginsenosides to bioactive compounds by intestinal microflora and its industrial application. J. Ginseng Res. 2009, 33, 165-176. [CrossRef]

45. Bae, E.-A.; Han, M.J.; Choo, M.-K.; Park, S.-Y.; Kim, D.-H. Metabolism of 20(S)- and 20(R)-ginsenoside Rg3 by human intestinal bacteria and its relation to in vitro biological activities. Biol. Pharm. Bull. 2002, 25, 58-63. [CrossRef] [PubMed]

46. Choi, W.Y.; Choi, W.S.; Kwon, H.S.; Lee, H.Y. Enhancement of low molecular weight ginsenosides from low-quality ginseng through ultra-high-pressure and fermentation processes. Eur. Food Res. Tech. 2013, 237, 429-440. [CrossRef]

47. Lee, J.H.; Hyun, Y.J.; Kim, D.H. Cloning and characterization of $\alpha$-L-arabinofuranosidase and bifunctional $\alpha$-L-arabinopyranosidase/ $\beta$-D-galactopyranosidase from Bifidobacterium longum h-1. J. Appl. Microbiol. 2011, 111, 1097-1107. [CrossRef]

48. Nicholson, J.K.; Holmes, E.; Wilson, I.D. Gut microorganisms, mammalian metabolism and personalized health care. Nat. Rev. Genet. 2005, 3, 431-438. [CrossRef]

49. Park, S.J.; Kim, D.H.; Paek, N.S.; Kim, S.S. Preparation and quality characteristics of the fermentation product of ginseng by lactic acid bacteria. J. Ginseng Res. 2006, 30, 88-94.

50. Delgado, S.; Florez, A.B.; Mayo, B. Antibiotic susceptibility of Lactobacillus and Bifidobacterium species from the human gastrointestinal tract. Curr. Microbiol. 2005, 50, 202-207. [CrossRef]

51. Dudek-Wicher, R.K.; Junka, A.; Bartoszewicz, M. The influence of antibiotics and dietary components on gut microbiota. Gastroenterol. Rev. 2018, 13, 85-92. [CrossRef] [PubMed]

52. Charteris, W.P.; Kelly, P.M.; Morelli, L.; Collins, J.K. Antibiotic susceptibility of potentially probiotic Lactobacillus species. J. Food Prot. 1998, 61, 1636-1643. [CrossRef] [PubMed]

53. Nam, S.J.; Lee, T.; Choi, M.-K.; Song, I.-S. Characterization of preclinical in vitro and in vivo pharmacokinetic properties of KPLA-012, a benzopyranyl 1,2,3-triazole compound, with anti-angiogenetic and anti-tumor progressive effects. Mass Spectrom. Lett. 2018, 9, 61-65.

54. Song, I.-S.; Choi, Y.A.; Choi, M.-K. Comparison of gastrointestinal permeability of caffeine, propranolol, atenolol, ofloxacin, and quinidine measured using chamber system and Caco-2 cell monolayer. Mass Spectrom. Lett. 2017, 8, 34-38.

55. Choi, Y.A.; Song, I.-S.; Choi, M.-K. Pharmacokinetic drug-drug interaction and responsible mechanism between memantine and cimetidine. Pharmaceutics 2018, 10, 119. [CrossRef]

56. Kwon, M.; Ji, H.-K.; Goo, S.H.; Nam, S.J.; Kang, Y.J.; Lee, E.; Liu, K.H.; Choi, M.-K.; Song, I.-S. Involvement of intestinal efflux and metabolic instability in the pharmacokinetics of platycodin D in rats. Drug Metab. Pharmacokinet. 2017, 32, 248-254. [CrossRef]

57. Choi, M.-K.; Jin, S.; Jeon, J.-H.; Kang, W.Y.; Seong, S.J.; Yoon, Y.-R.; Han, Y.-H.; Song, I.-S. Tolerability and pharmacokinetics of ginsenosides $\mathrm{Rb} 1, \mathrm{Rb} 2, \mathrm{Rc}, \mathrm{Rd}$, and compound $\mathrm{K}$ after single or multiple administration of red ginseng extract in human beings. $J$. Ginseng Res. 2018, 44, 229-237. [CrossRef]

58. Jeon, J.H.; Lee, J.; Lee, C.H.; Choi, M.K.; Song, I.-S. Correlation between the content and pharmacokinetics of ginsenosides from four different preparation of panax ginseng C.A. Meyer in rats. Mass Spectrom. Lett. 2021, 12, 16-20.

59. Kwon, M.; Jeon, J.-H.; Choi, M.-K.; Song, I.-S. The development and validation of a novel "dual cocktail" probe for cytochrome P450s and transporter functions to evaluate pharmacokinetic drug-drug and herb-drug interactions. Pharmaceutics 2020, 12, 938. [CrossRef]

60. Jeon, J.-H.; Lee, S.; Lee, W.; Jin, S.; Kwon, M.; Shin, C.H.; Choi, M.-K.; Song, I.-S. Herb-Drug interaction of red ginseng extract and ginsenoside Rc with valsartan in rats. Molecules 2020, 25, 622. [CrossRef]

61. Kim, M.; Park, M.H.; Nam, G.; Lee, M.; Kang, J.; Song, I.S.; Choi, M.K.; Jin, H.K.; Bae, J.S.; Lim, M.H. A glycosylated prodrug to attenuate neuroinflammation and improve cognitive deficits in Alzheimer's disease transgenic mice. Mol. Pharm. 2021, 18, 101-112. [CrossRef] [PubMed]

62. Song, I.-S.; Jeong, H.-U.; Choi, M.-K.; Kwon, M.; Shin, Y.; Kim, J.H.; Lee, H.-S. Interactions between cyazofamid and human drug transporters. J. Biochem. Mol. Toxicol. 2020, 34, e22459. [CrossRef] [PubMed]

63. Yoo, J.M.L.; Lee, J.Y.; Lee, Y.G.; Back, S.Y.; Kim, M.R. Enhanced production of compound K in fermented ginseng extracts by Lactobacillus brevis. Food Sci. Biotechnol. 2019, 28, 823-829. [CrossRef]

64. Lee, N.-K.; Paik, H.-D. Bioconversion using lactic acid bacteria: Ginsenosides, GABA, and phenolic compounds. J. Microbiol. Biotechnol. 2017, 27, 869-877. [CrossRef] [PubMed]

65. Renchinkhand, G.; Park, Y.W.; Song, G.-Y.; Cho, S.-H.; Urgamal, M.; Bae, H.C.; Choi, J.W.; Nam, M.S. Identification of $\beta$ glucosidase activity of Enterococcus faecalis CRNB-A3 in Airag and its potential to convert ginsenoside Rb1 from panax ginseng. J. Food Biochem. 2016, 40, 120-129. [CrossRef]

66. Kim, D.-H. Gut microbiota-mediated pharmacokinetics of Ginseng saponins. J. Ginseng Res. 2017, 42, 255-263. [CrossRef]

67. Westerhout, J.; van de Steeg, E.; Grossouw, D.; Zeijdner, E.E.; Krul, C.A.; Verwei, M.; Wortelboer, H.M. A new approach to predict human intestinal absorption using porcine intestinal tissue and biorelevant matrices. Eur. J. Pharm. Sci. 2014, 63, 167-177. [CrossRef]

68. Volpe, D.A. Permeability classification of representative fluoroquinolones by a cell culture method. AAPS PharmSci 2004, 6, 1-6. [CrossRef] 
69. Paixão, P.; Gouveia, L.F.; Morais, J.A. Prediction of the in vitro permeability determined in Caco-2 cells by using artificial neural networks. Eur. J. Pharm. Sci. 2010, 41, 107-117. [CrossRef]

70. Barber, H.; Hawksworth, G.; Kitteringham, N.; Petersen, J.; Petrie, J.; Swann, J. Protein binding of atenolol and propranolol to human serum albumin and in human plasma [proceedings]. Br. J. Clin. Pharmacol. 1978, 6, 446-447. [CrossRef]

71. Van Steeg, T.; Boralli, V.; Krekels, E.; Slijkerman, P.; Freijer, J.; Danhof, M.; de Lange, E. Influence of plasma protein binding on pharmacodynamics: Estimation of in vivo receptor affinities of $\beta$ blockers using a new mechanism-based PK-PD modelling approach. J. Pharm. Sci. 2009, 98, 3816-3828. [CrossRef] [PubMed]

72. Kim, J.K.; Choi, M.S.; Jeung, W.; Ra, J.; Yoo, H.H.; Kim, D.H. Effects of gut microbiota on the pharmacokinetics of protopanaxadiol ginsenosides Rd, Rg3, F2, and compound K in healthy volunteers treated orally with red ginseng. J. Ginseng Res. 2020, 44, 611-618. [CrossRef]

73. Yoo, S.; Park, B.-I.; Kim, D.-H.; Lee, S.; Lee, S.-H.; Shim, W.-S.; Seo, Y.; Kang, K.; Lee, K.-T.; Yim, S.-V.; et al. Ginsenoside Absorption rate and extent enhancement of black ginseng (CJ EnerG) over red ginseng in healthy adults. Pharmaceutics 2021, 13, 487. [CrossRef] [PubMed]

74. Jiang, R.; Dong, J.; Li, X.; Du, F.; Jia, W.; Xu, F.; Wang, F.; Yang, J.; Niu, W.; Li, C. Molecular mechanisms governing different pharmacokinetics of ginsenosides and potential for ginsenoside-perpetrated herb-drug interactions on OATP1B3. Br. J. Pharmacol. 2015, 172, 1059-1073. [CrossRef]

75. Chiu, N.T.C.; Guns, E.S.T.; Adomat, H.; Jia, W.; Deb, S. Identification of human cytochrome P450 enzymes involved in the hepatic and intestinal biotransformation of 20(S)-protopanaxadiol. Biopharm. Drug Dispos. 2013, 35, 104-118. [CrossRef] [PubMed] 